\title{
Impact of anchorage miniscrews in multibracket treatments without extractions
}

\author{
P. Baron \\ Private practice in Colomiers (Toulouse) \\ Head of the orthodontics department - Université Paul Sabatier - Toulouse
}

\begin{abstract}
Over the past decade, the interest for miniscrews is continuously growing as confirmed by the amount of recent published studies. In particular, their use allows to make corrections in a single phase and avoids extractions of premolars, while keeping usual goals of treatment. Main results of pilot studies and some clinical examples are presented here to illustrate our therapeutic approach for the treatment of tooth discrepancy in Class I, Class II and Class III situations.
\end{abstract}

\section{KEY WORDS}

Miniscrews, mini-implant, Temporary Anchorage Device (TAD), non extraction, multibraces treatments, skeletal anchorage

The use of anchorage screws is becoming a standard practice in orthodontics today. The growing interest of practitioners from around the world is obvious simply by counting the number of articles describing it published in the international literature during the last ten years. If we do a search on PubMed by using the key words ("Orthodontic Anchorage Procedures" [Mesh] AND [lorthodontic AND miniscrew) OR (orthodontic AND mini implant) OR (orthondontic AND skeletal anchorage) OR lorthodontic AND temporary anchorage device)] more than 320 publications appear between 2002 and 2013. Since the very first clinical articles ${ }^{56,70}$, a great number of other treated cases have been published with sometimes outstanding results $1,2,31-33,36,52,57,66,67$. The list of comparative studies $7,21,30,39,44$, experimental studies $^{26,45,51}$, some randomized clinical trials ${ }^{7,35,38,71}$ ' and systematic reviews ${ }^{14,16,20,22,43}$ has continued to grow over the years. This can be seen as evidence for an ongoing therapeutic revolution that is impacting all aspects of orthodontics and that is suggesting new solutions for

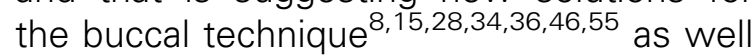


as for lingual orthodontics, 29,37,41,69, for the aligner technique ${ }^{11,73}$ or for orthopaedics $^{13}$.

Among these anchorage screws, miniscrews, originally called miniimplants in Korea, are a minimally invasive surgical option, with a low failure rate $9,47,59,72$ and with excellent patient acceptance ${ }^{5,27,33}$. Their potential has been demonstrated repeatedly during multibracket treatments for mesial movements ${ }^{3,23}$, for molar distalization $^{25,53,61,62}$, for intrusion ${ }^{18,64,65}$, for extrusion ${ }^{10,12}$, for "in masse" retraction of anterior teeth ${ }^{19,57,69}$, or for maintaining anchorage in cases of premolar extractions $35,39,44$. A recent meta-analysis provides an update on their results compared to those obtained with extraoral force ${ }^{43}$ and demonstrates greater anterior retraction and less loss of posterior anchorage with miniscrews. Their importance for reducing treatment time as well as for providing "absolute" anchorage has been demonstrated many times over $^{17,24,43,50,60,68}$ and they are often used as a replacement for extraoral forces when managing extraction spaces.

Nevertheless, existing studies that highlight their use in cases without extraction are either rare or have limited readership ${ }^{6,40,54}$. However, it provides us with an extraordinary tool that makes it possible to respond to a whole series of typical clinical situations that are regularly treated by expansion with varying harmful consequences for the patient because it is based on concepts which neglect the anterior limits of the dentition, or sacrifice the premolars when these limits are respected.

to best respond to each situation that is encountered. The surgical conditions must, in addition to following a well established placement protocol, respect anatomical demands for neutrality with regard to the mucosa, dental roots and vascular nerve endings.

The biomechanics must take into consideration the different elements of the force system especially the location of the center of gravity of the teeth and of tooth groups as well as their anchorage value. With this in mind, we, at the university of Toulouse, used a 3D imaging research method to generate a computerized reconstruction of the data $^{48,49}$. The mechanics as such 


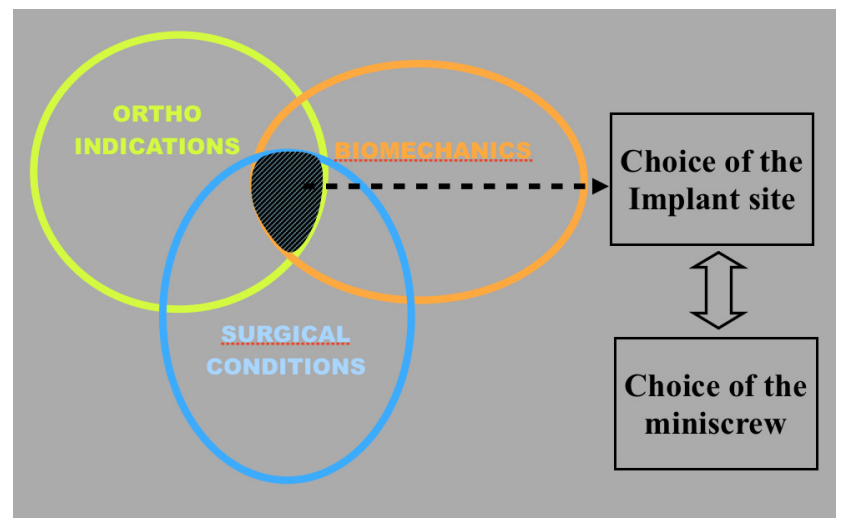

Figure 1

Choice of the site and of the miniscrews conditioned on the three types of factors.

can be performed with direct anchorage, with indirect anchorage or with a combination of both anchorage systems. The orthodontic indication also depends directly on the patient and on his malocclusion. Orthodontics procedes sagittally with distalization and mesialization therapies accompanied by a clockwise or counterclockwise rotation of the occlusal plane. The miniscrews provide us with the possibility that until now didn't exist to regulate the force by controlling the harmful secondary effects of the mechanics. Since there is crowding without extractions, it will be necessary to create space, most frequently in both the arches, in order to resolve the anterior arch length discrepancy while at the same time following the logic dictated by the occlusal imbalance.

\section{INDICATIONS FOR TYPES OF MINISCREW ANCHORAGE IN THE LATERAL POSITION FOR TREATMENT WITHOUT EXTRACTION}

In general, miniscrews should be placed wherever anchorage is necessary. Therefore, when treating for an anterior space deficit, the anchorage will be insufficient in the posterior zone and so the screws should be optimally inserted in the lateral areas. Miniscrews provide adequate anchorage to reliably stabilize an arch that in turn serves as anchorage for the opposing arch, so only two miniscrews will be utilized for most treatments. Intermaxillary elastics will ensure the connection for a short time during the leveling phase of the opposite (non-miniscrew) arch.

For a class II, the anchorage is critical on the upper jaw and the screws should be inserted into the maxillary bone, in the premolar or molar area. If it is class III, anchorage requirements are still posterior but in this case on the lower jaw and the screws should consequently be placed in the lower molar zone.

We can provide some specific indications that correspond to the type 


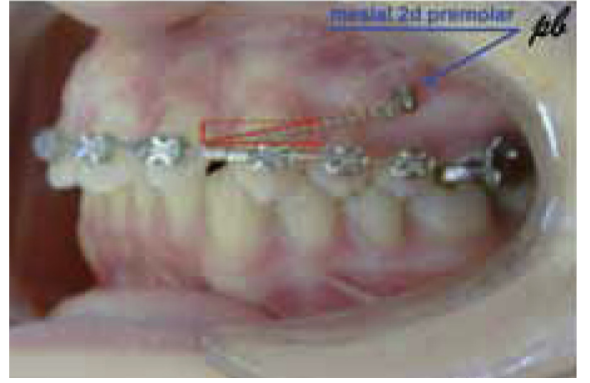

Figure 2

Clinical situation.

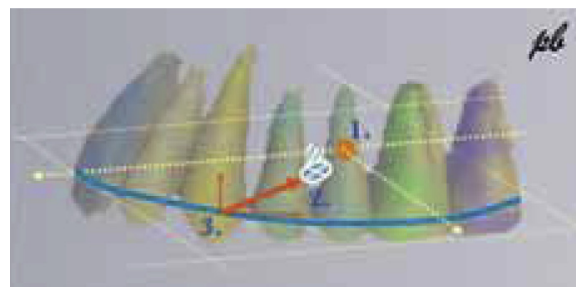

Figure 3

Mechanical analysis. 1. Center of resistance of the arch. 2. Miniscrews. 3. Point of application, vertical and anteroposterior components of the force.

of tie that connects the miniscrews to arch system:

- with an elastic link (stretched spring - elastomeric module power chain): we use direct mechanics since its impact can be analyzed by differentiating between the various forces exerted on the teeth (Fig. 2 and 3). This process allows for an en masse distalization, a vertical intrusion force and an increase of anchorage on the arch. Miniscrews can be inserted in inter-radicular sites in front of the second premolars - mesial position 5 (or $\mathrm{m} 5$ ) - or in front of the first molars - mesial position 6 (or m6). The typical indications are comprised of a class II occlusion, a class I with moderate crowding, a bimaxillary protrusion. Taking into account the posterior crowding and the extent of the required distalization, the orthodontist will have to consider extraction or non-extraction of the toothbuds of U8/L8 or extraction of U7/L8 when the substitution of U7 with U8 is possible:

- with a rigid link: the miniscrew is attached to the archwire with a metallic ligature that will perform a archwire-teeth-miniscrew system capable of moving in rotation around a fixed point represented by the miniscrew. We use indirect mechanics with a premolar by pass and a compressed spring at this location on the archwire to move teeth by groups, depending on the balance of forces achieved (Fig. 4 and 5). Here also the miniscrews can be placed in the mesial $5(\mathrm{~m} 5)$ or in the mesial 6 (m6) and the need for enucleation of the wisdom teeth and substitution of the second molars has to be studied. The intensity of forces is applied by the degree of compression of the spring. Posteriorly, the molar receives a

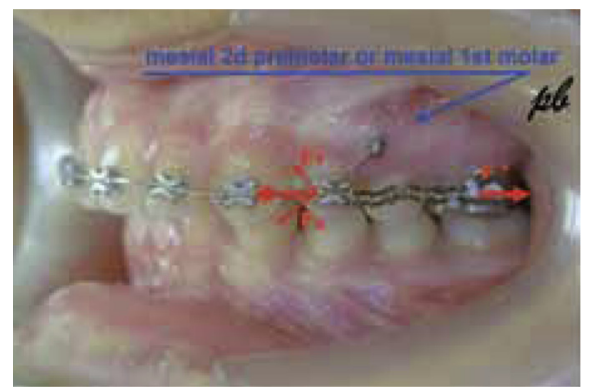

Figure 4

Indirect anchorage system: buccal technique. 


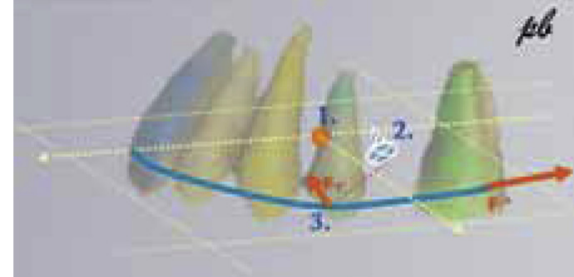

Figure 5

Mechanical analysis. 1. Center of resistance of the arch displaced towards the front. 2. Miniscrews. 3. Application point, tangential component of intrusion and molar distalizing force.

horizontal distalizing force. Anteriorly, only a tangential component persists and its impact can vary based on the number of teeth engaged in the system, from the position of the point of application of force and the position of the miniscrew. Therefore, we will have optimal indications for this type of mechanics when the goal is the distalization of molars, movements for sectional intrusion of tooth groups and an increase in anchorage, especially in the vertical direction. These indications are appropriate for skeletal and dental class skeletal and dental class II malocclusions, for class I malocclusions with arch length discrepancy and vertical discrepancies particularly incisor overbite.

Placing a system on the inferior arch is delayed. Treatment management can be carried out with good

\section{EFFECTS OF THE MECHANICS}

The movements on the upper arch are controlled both by the mechanics of the arch wire and by the force system whose parameters can be results when the molar and premolar relationships are such that a distalization of this arch is possible, by providing, after being uprighted, space for the resolution of anterior crowding or for the levelling of the Curve of Spee. It's not necessary to use additional miniscrews for this phase. Vertical intermaxillary elastics or class III elastics worn cooperatively will ensure adequate control of the incisor position that is consistent with the treatment goals (Fig. 6). This means that for most cases the patient must wear the elastics for a period of one to four months. They are generally well-tolerated and the wear time is short in comparison with the demands required for a class II intermaxillary mechanics that in this case is not necessary. In fact, the discrepancy of a class $\|$ is quickly corrected at the beginning of treatment by the multiple actions of the mechanics on the miniscrews. Moreover, this correction takes place without any extraoral force, without wearing elastics, without any volumetric expander system or in other words without any discomfort for the patient. Cooperation is mainly focused on hygiene and on respecting the prescribed wear time of the appliance. In the same way, when there are asymmetric relationships, differential activations can be made from one side to the other.

modulated. The sequence of therapeutic steps is well established with perfectly reproducible results. The indications make it possible to 


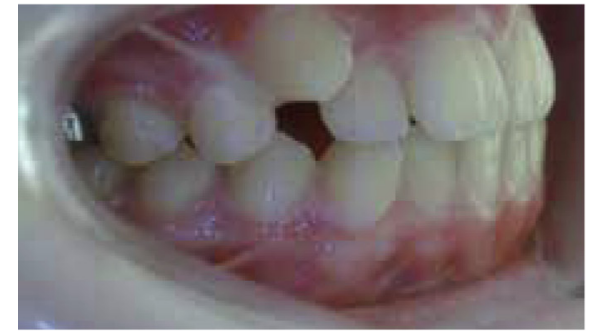

a

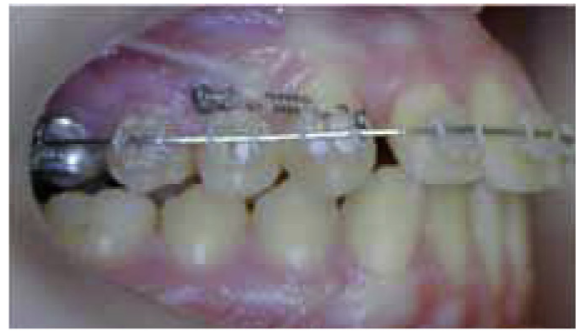

b

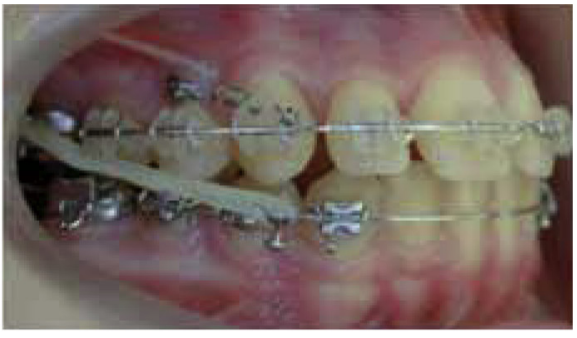

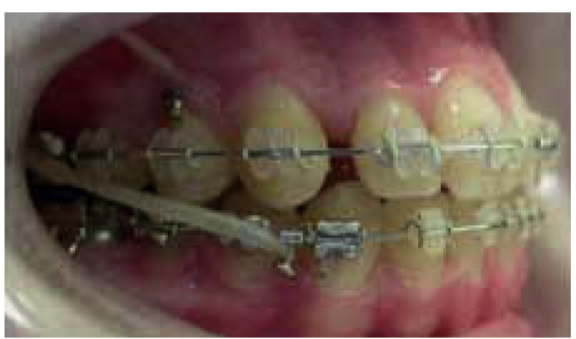

d

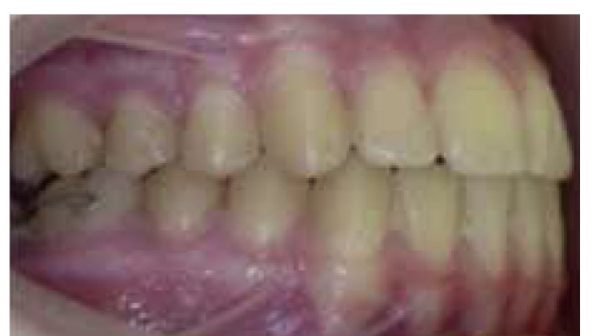

e

Figure 6

a: initial situation with minor class II and crowding on both arches. b: correction using miniscrews (m5 - direct anchorage); the crowding and the class I are overcorrected in a few months (+6 months). c. lower premolar and lower canine disalization incisor Class III elastics. d: incisor alignment after distal uprighting/straightening of the lateral groups: total wear of the elastics = 3 months. e: final (+ 18 months).

treat a wide range of clinical cases especially class II malocclusions. The findings of several studies our several studies ${ }^{6,40,54}$ converge and show the main results that we can expect from this type of therapy. In 2008, in the context of a clinical research report written at the end of a post-graduate, we compared the cephalometric tracings before/after treatment of 30 patients ages 11 to 15 at the beginning of treatment. All the cases were randomly chosen from a cohort of 96 treated patients, selected according to exclusion and inclusion criteria, who had all been successfully treated with miniscrews using direct or indirect mechanics. The screws were symmetrically inserted in position m5 or m6. The local superimpositions were done based on the bi-spinal plane registered on the anterior naso-pala- tal canal. The results show a $10^{\circ}$ distal torque of the molars, nearly $2 \mathrm{~mm}$ of intrusion and more than $3 \mathrm{~mm}$ distalization of the mesial cuspid (Table I).

In 2009, another study was conducted on a series of 22 consecutive cases, ages 12 to 15 , all of whom had been successfully treated with the same mechanics, showed very similar results measuring $8^{\circ}$ distal torque, $1.8 \mathrm{~mm}$ of intrusion and $2.5 \mathrm{~mm}$ of distalization of the maxillary first molars. A Procrustes analysis of the data using geometric morphometry shows, concomitantly with the retraction and molar retrusion, an backwards elevation of the occlusal plane that accompanies a mandibular anti-rotation.

In 2012, a third research work that also used a Procrustes analysis, on a 


\begin{tabular}{|c|c|c|c|c|c|}
\cline { 2 - 5 } \multicolumn{1}{c|}{} & Average & Std. Dev. & Std. Error & Minimum & Maximum \\
\hline d V6 & 10,226 & 6,699 & 1,223 & -3 & 19 \\
\hline d I6 & 1,877 & 1,376 & 0,251 & 0 & 5 \\
\hline d R6 & $-3,145$ & 1,401 & 0,255 & -6 & -1 \\
\hline
\end{tabular}

Table I

Movement of the maxillary first molar before/after treatment $(N=30), 2008$.

\begin{tabular}{|l|}
\hline Sella \\
\hline Basion \\
\hline Nasion \\
\hline ENA \\
\hline ENP \\
\hline Point A \\
\hline Point B \\
\hline Chin \\
\hline Gonion \\
\hline Gnathion \\
\hline Joint \\
\hline Sup. inc. edge \\
\hline Sup. inc. apex \\
\hline $\begin{array}{l}\text { Free edge } \\
\text { inf. Inc. }\end{array}$ \\
\hline Inf. inc. apex \\
\hline
\end{tabular}

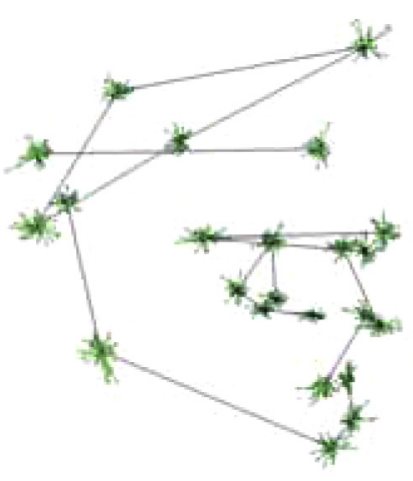

Figure 7

Variability of the points from the study before treatment $(N=30) 2012$ - with Procrustes analysis software $=$ APS v2.4 (Dr. Penin).

series of 30 consecutive cases had findings showing the same therapeutic benefits illustrated in Figures 7 and 8 .

These pilot studies suggest that we have achieved excellent control of the maxillary arch where the miniscrews are implanted, adequate

\section{CLINICAL CASES}

These mechanics present the advantages of creating available space on the arch, that radically changes the therapeutic extraction approach.

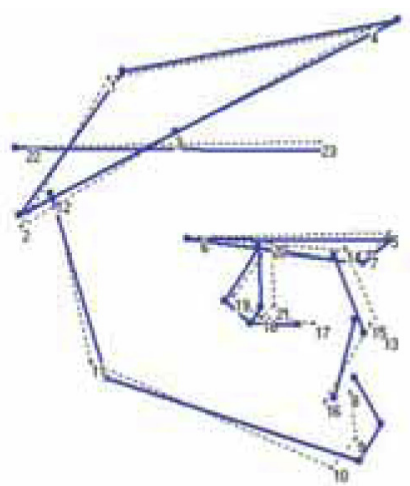

Figure 8

Schematic of the variations before treatment (dashed graph lines)/after treatment (blue) showing the intrusion and the distalization of molars, retraction of the incisors, the projection of the pogonion due to mandibular anti-clockwise rotation.

anchorage for the management of the opposite arch and that the effects go well beyond dental movements, especially due to very significant skeletal repercussions in the treatment of class II discrepancies or in cases of anterior crowding.

The following clinical examples show the results for three different types of malocclusion. 

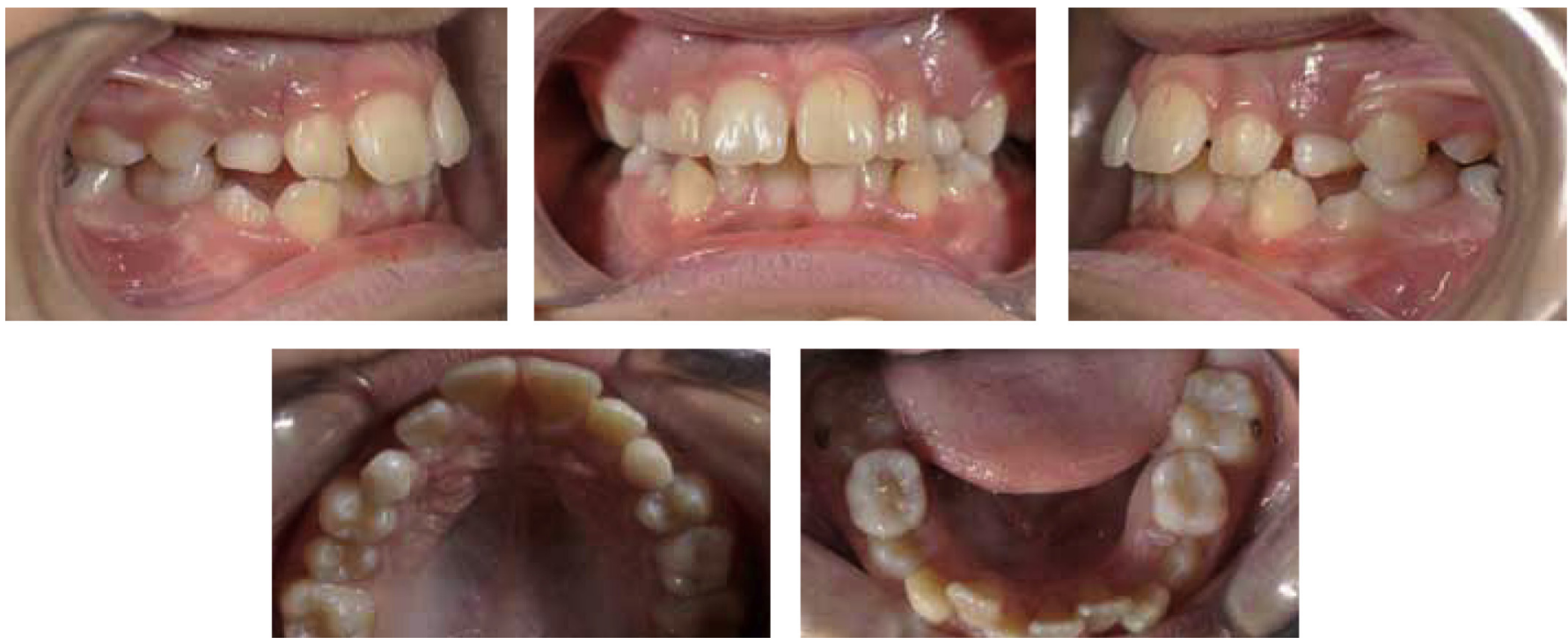

Figure 9

Pre-treatment: occlusal relationships at the end of the mixed dentition.

Case $n^{\circ} 1$

Cassiopé, a young girl, 11 years old, presents with severe crowding on the mandibular arch in the mixed dentition. The anteroposterior relationships are in class I (Fig. 9). Without incurring any particular risk, the treatment will be delayed until the permanent dentition phase. We will only install a lingual arch wire in the meantime, in order to conserve the E space on the lower arch.

Figures 10, 11 and 12 present the basic elements of the clinical picture. The relationships are in class I

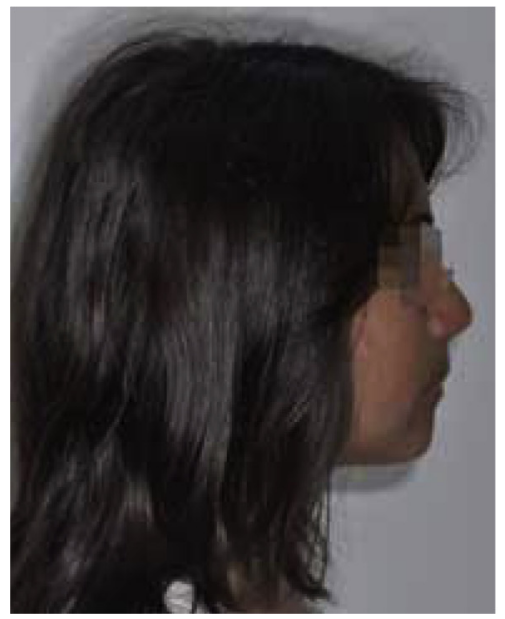

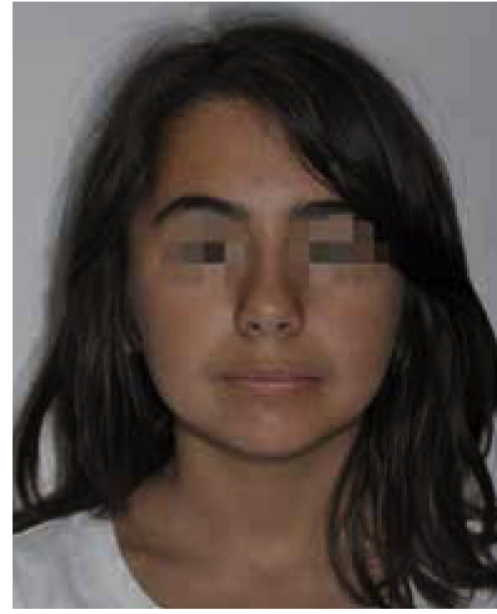

Figure 10

Extraoral views before treatment.

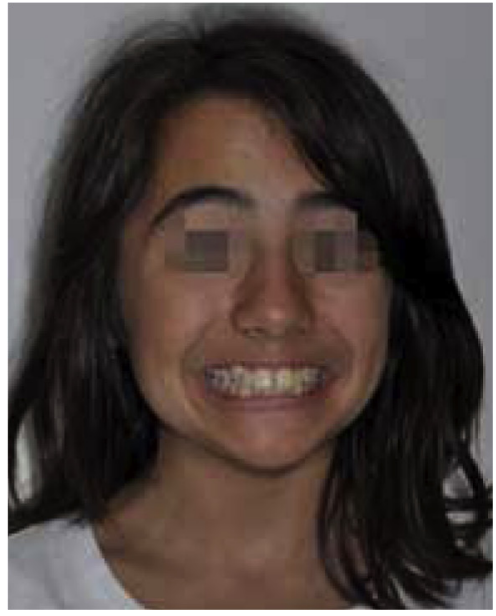



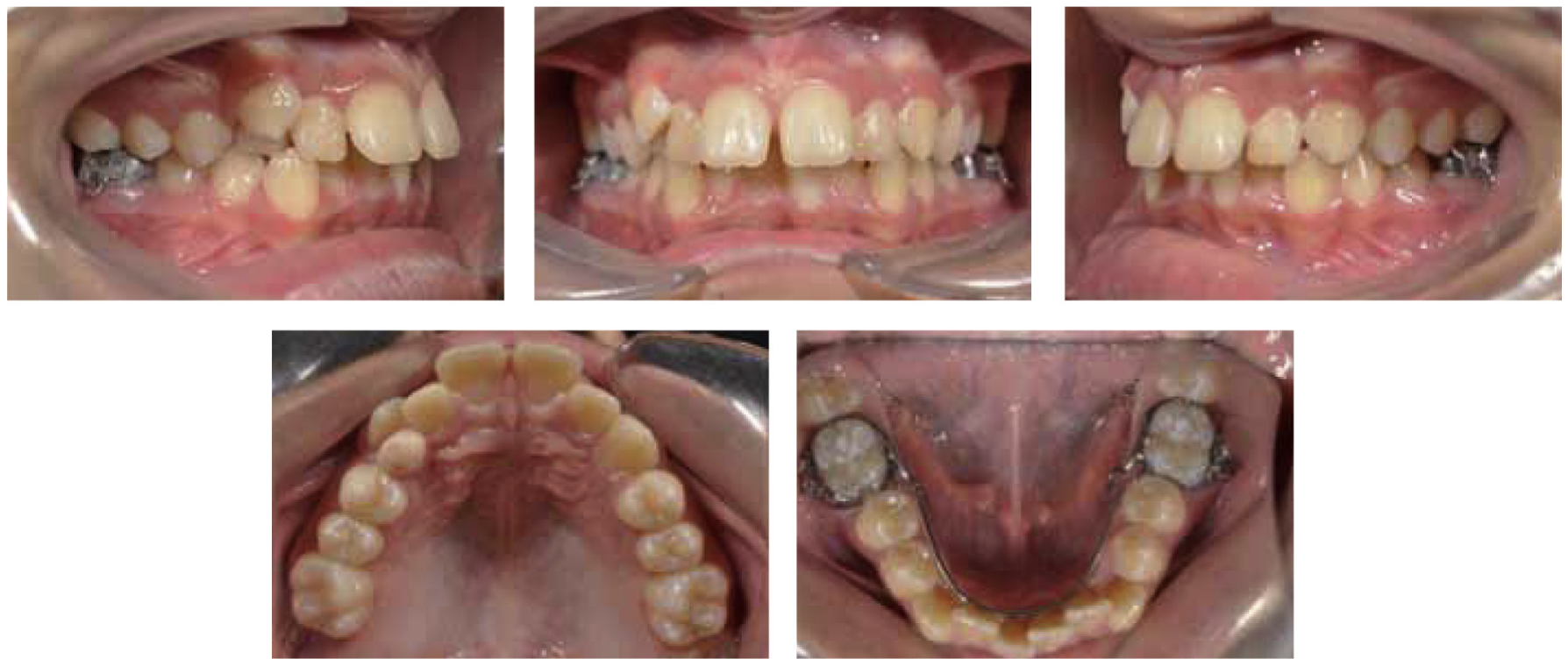

Figure 11

Intraoral views before treatment clearly showing the class I and the mandibular crowding.

occlusion with bimaxillary protrusion of the incisors; the mandibular crowding is $6 \mathrm{~mm}$. The objectives of treatment aim to correct the malocclusion, improve the skeletal structure and respect the parameters of the arch. The slightly protruded mandibular incisors will not be repositioned given the whole complex of dento-alveolar relationships.

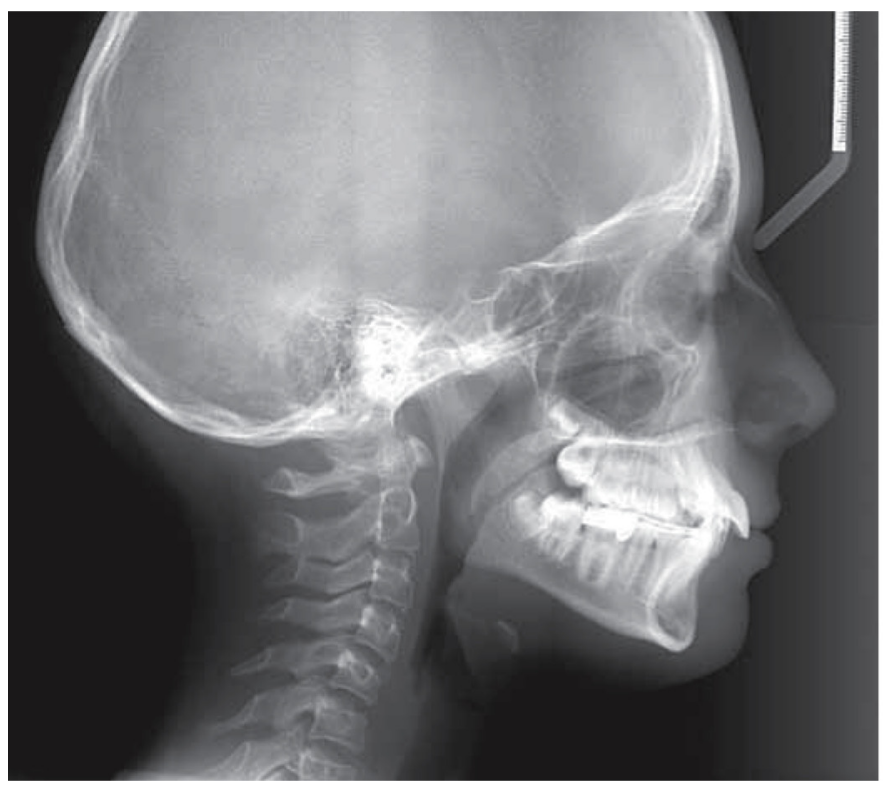

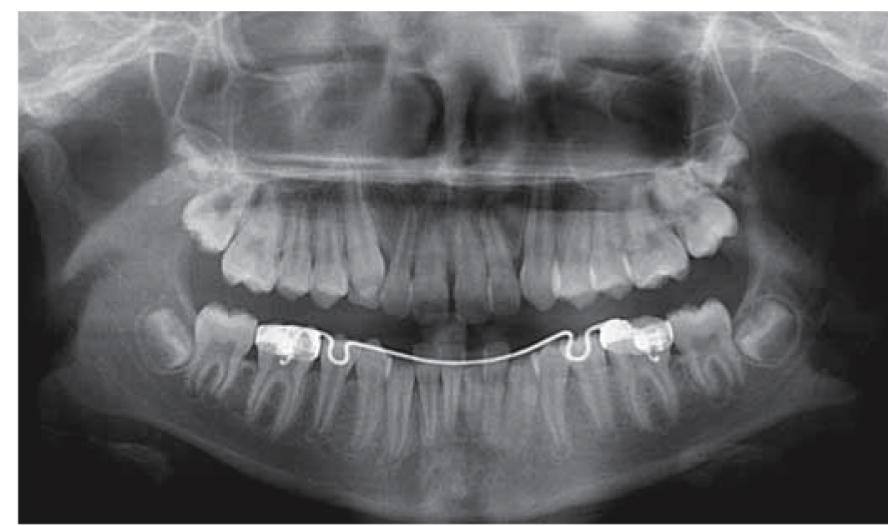

Figure 12

Xrays before treatment. 

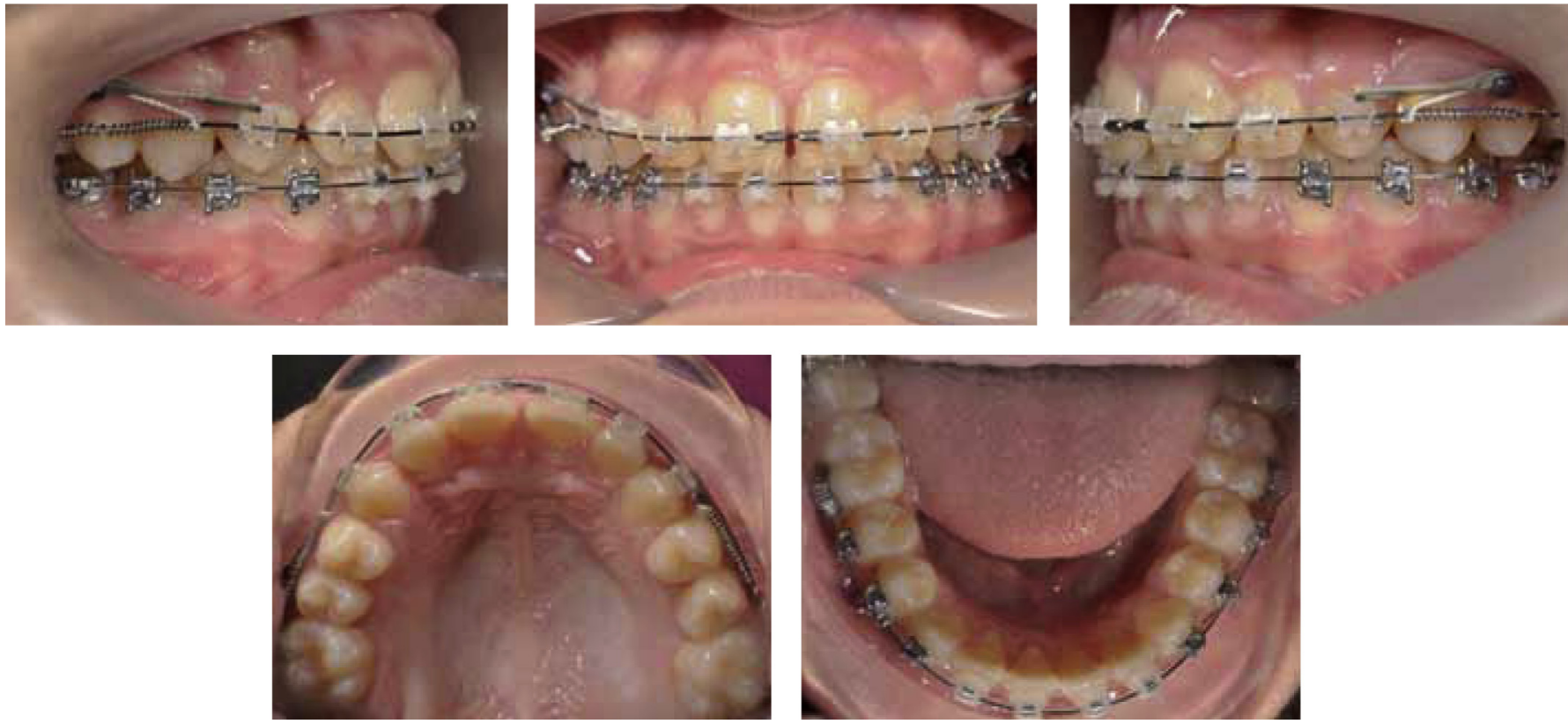

Figure 13

Therapeutic phase of anterior retraction.

The treatment plan specifies the use of miniscrews $(1.2 \mathrm{~mm}$ diameter $-7 \mathrm{~mm}$ long) in the $\mathrm{m} 6$ position (Fig. 13).

The end of treatment is reached in less than two years. The anterior

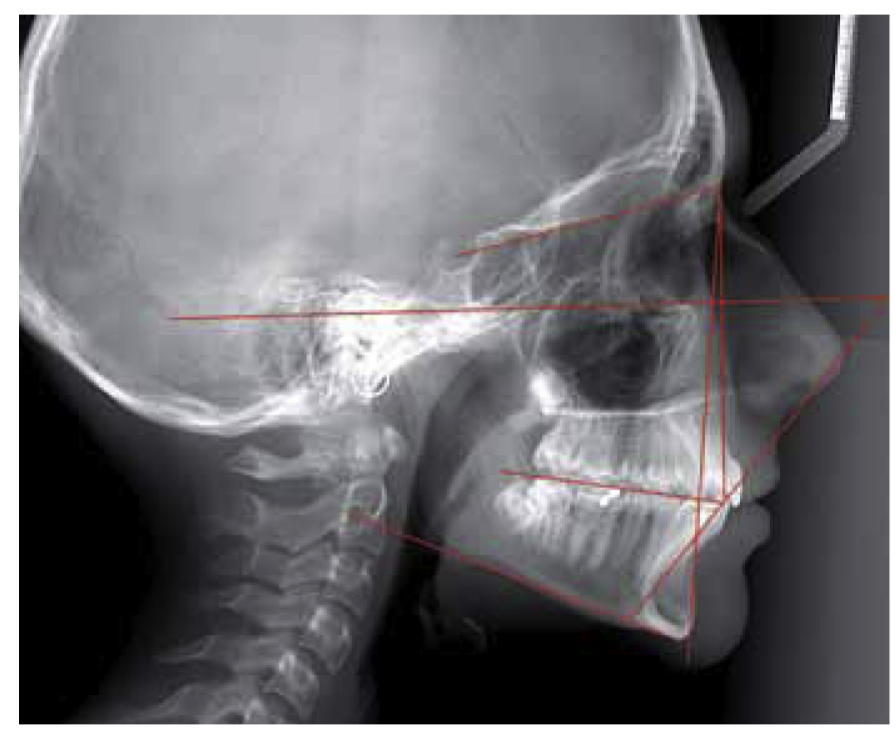

relationships are corrected and the arches are aligned (Fig. 15 and 16). The position of the inferior incisor has been controlled (Fig. 14). Two maxillary miniscrews were

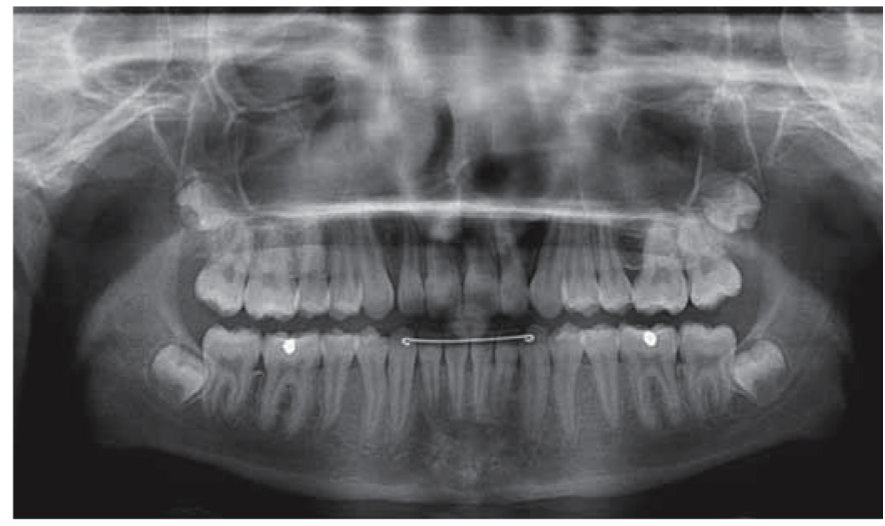

Figure 14

Xrays after treatment. 

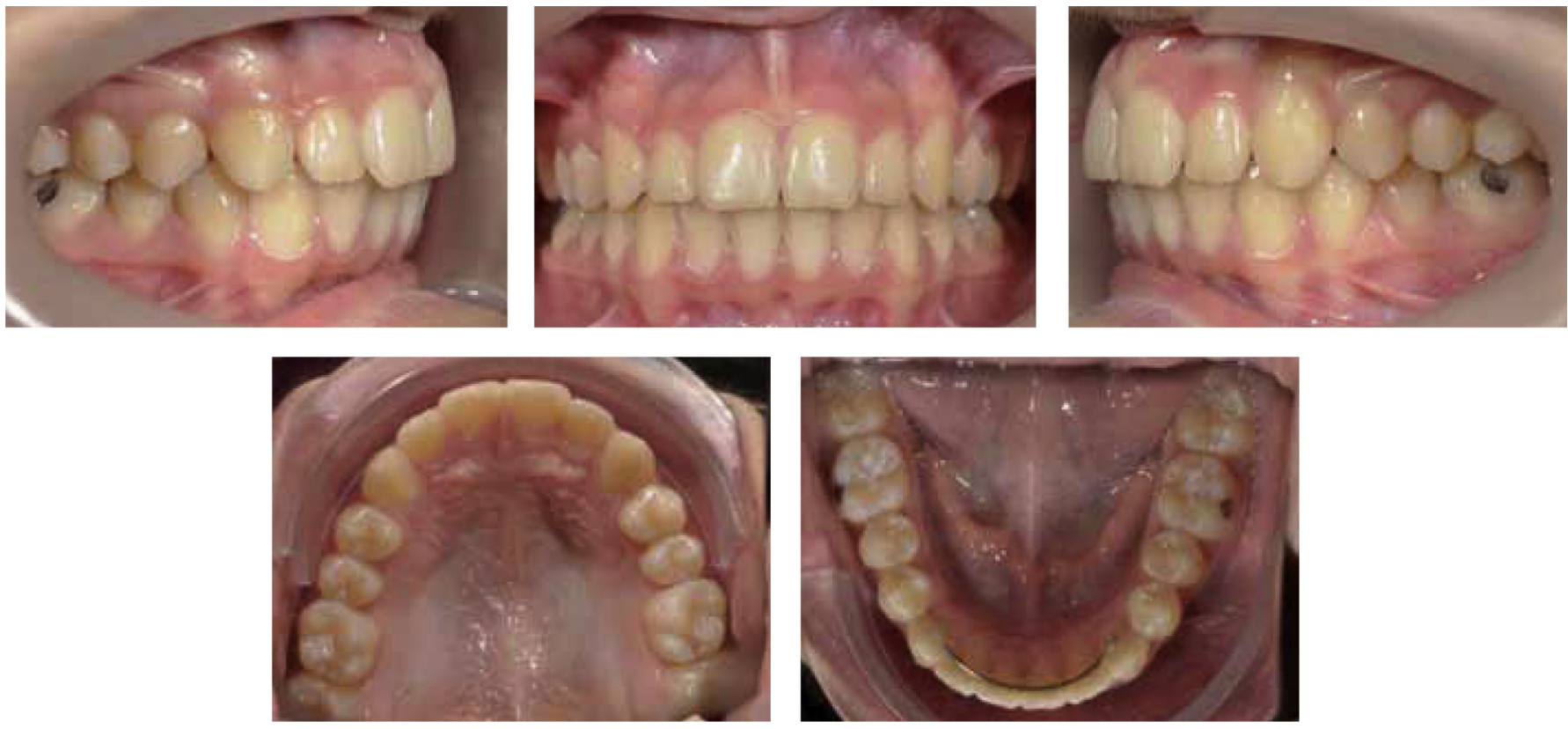

Figure 15

Intraoral views at the end of treatment: duration $=22$ months.
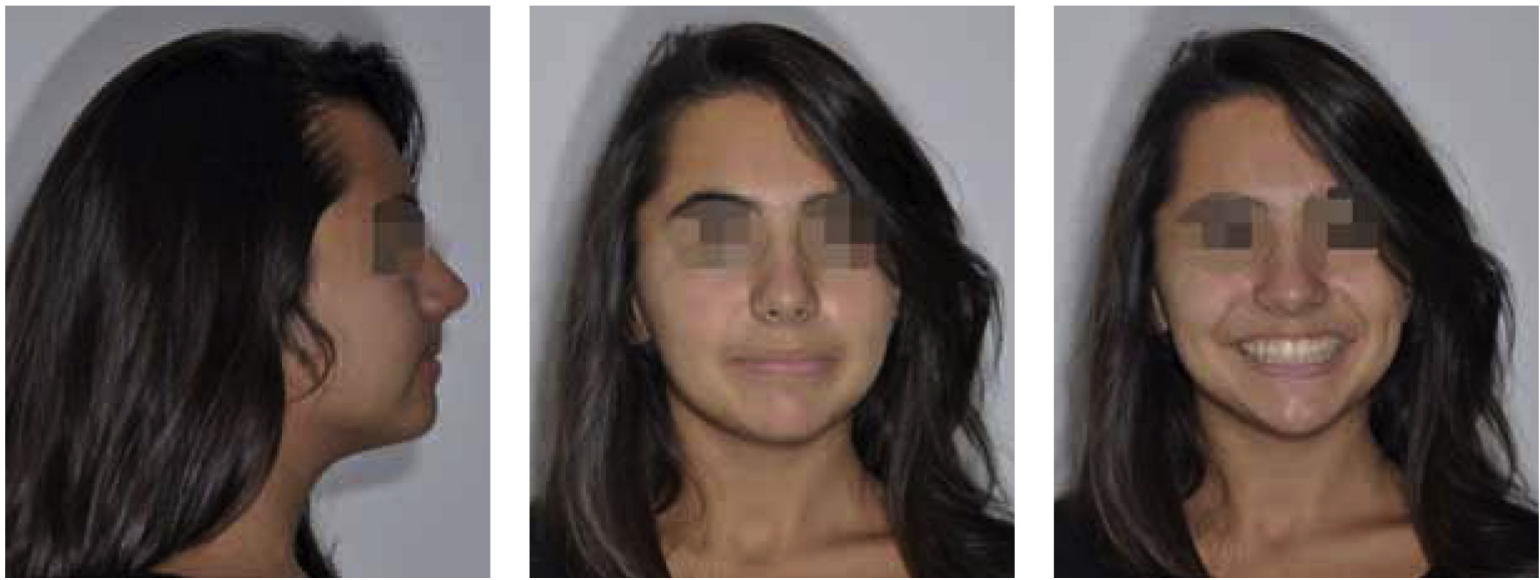

Figure 16

Extraoral views after treatment.

used; Class III elastics were worn for 3 months during the mandibular preparation. No other removable appliance was necessary. The wisdom teeth should be regularly monitored.

\section{Case $n^{\circ} 2$}

The miniscrews used according to our protocol are exceedingly important for the treatment of class II malocclusions. In a normodivergent facial 

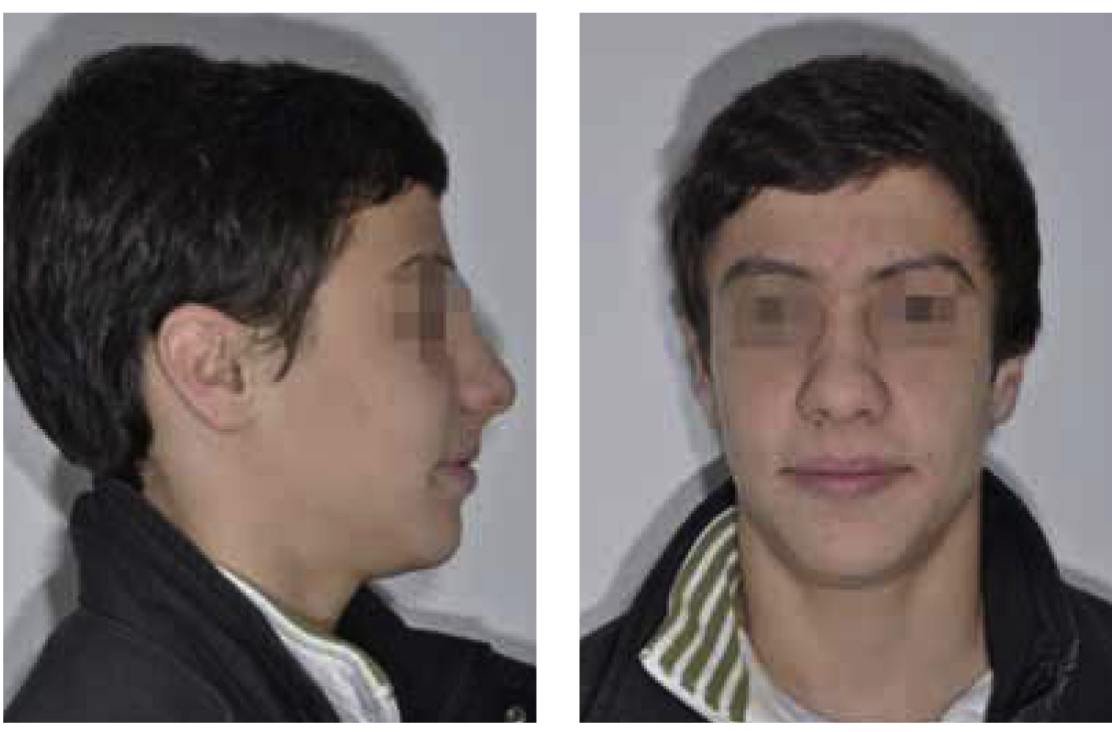

Figure 17

Extraoral views clearly showing the disruption of the profile and the smile.
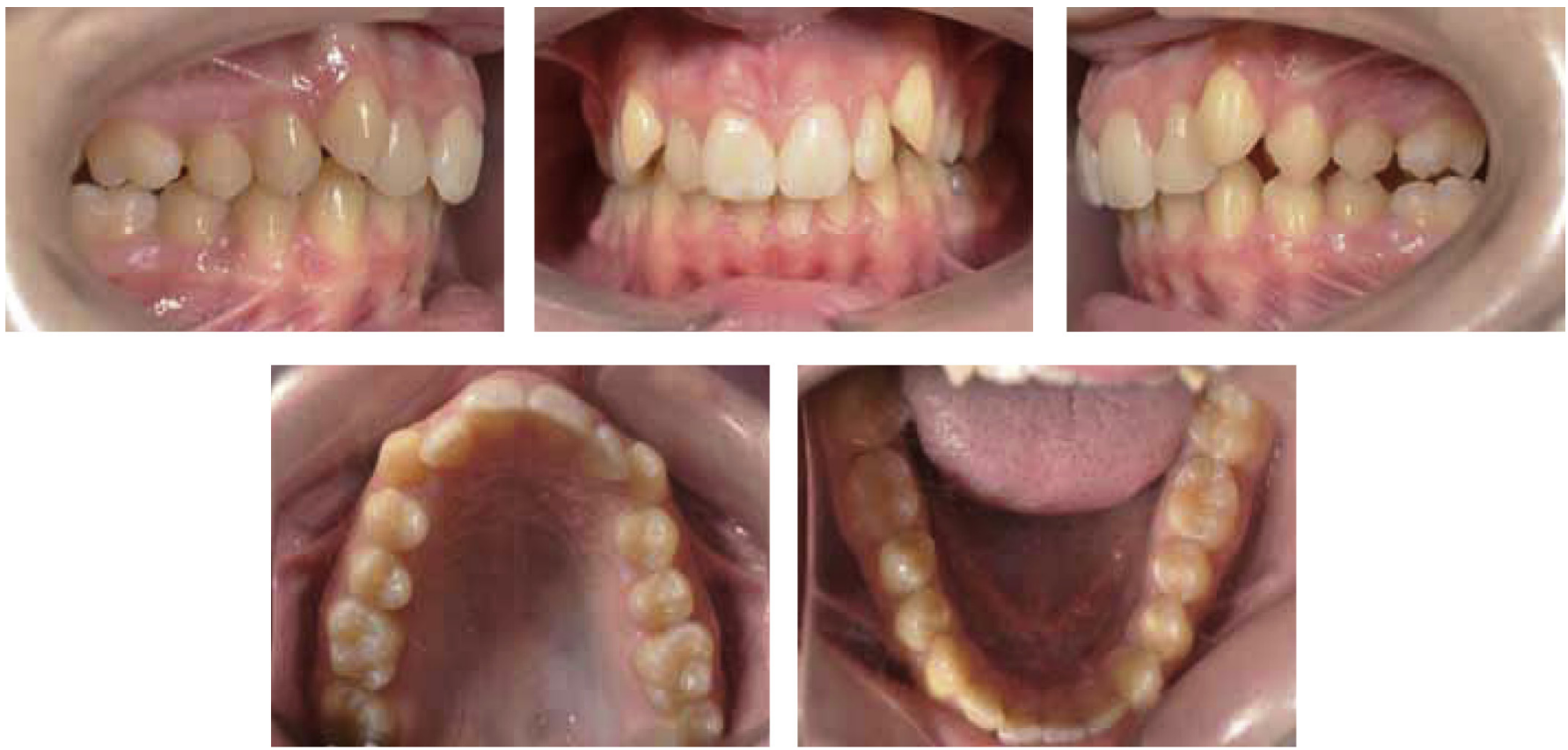

Figure 18

Intraoral views of the bilateral class // occlusion. 

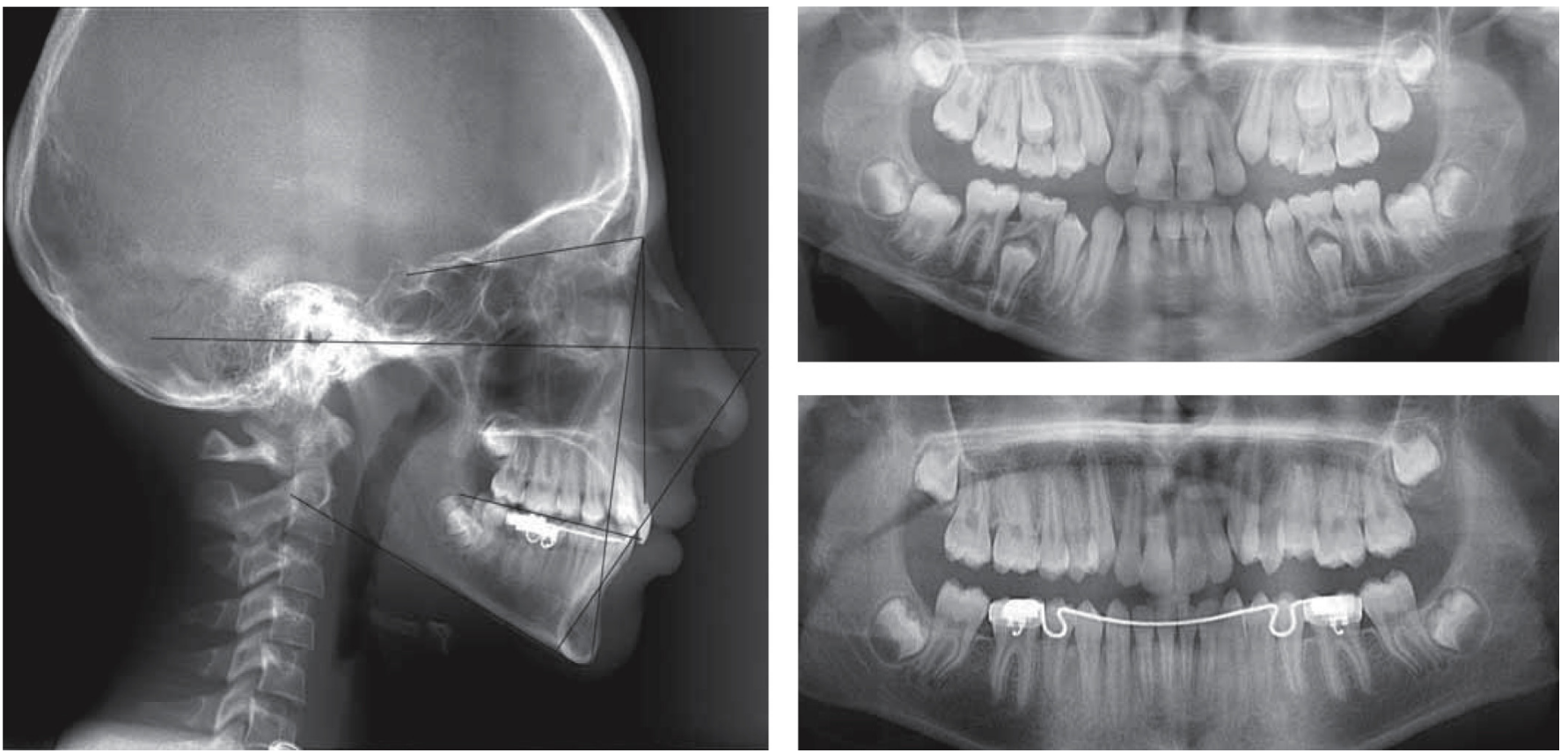

Figure 19

Xrays before treatment.
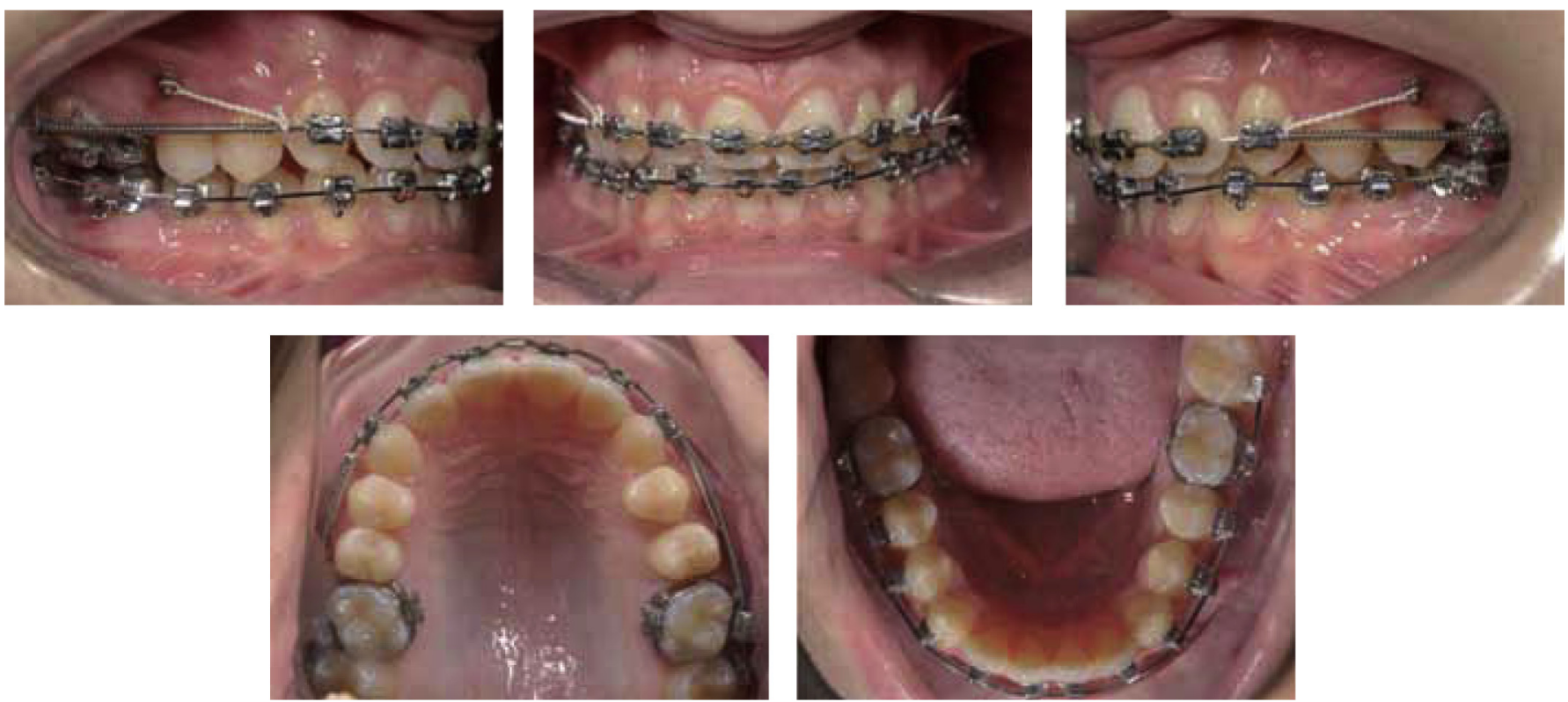

Figure 20

End of the phase of mandibular leveling. 

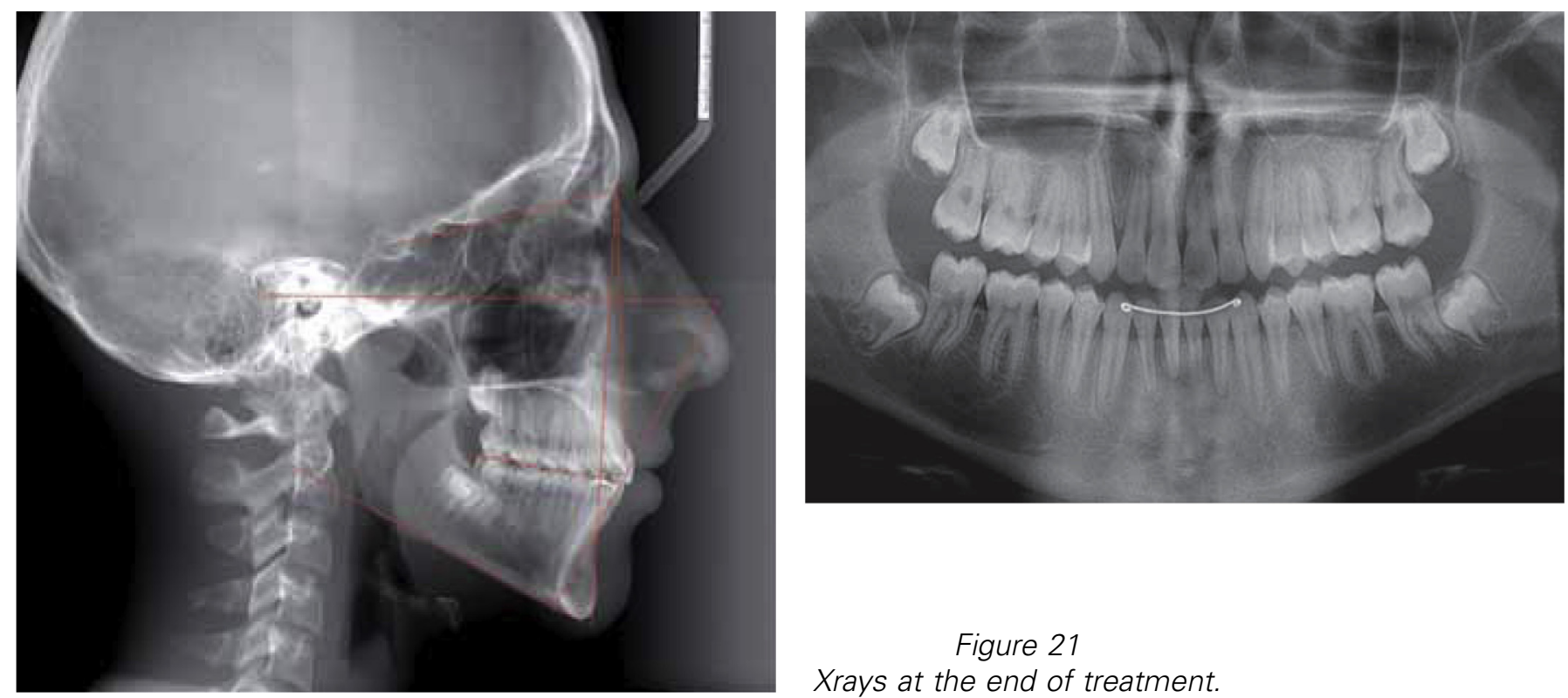

Figure 21

Xrays at the end of treatment.
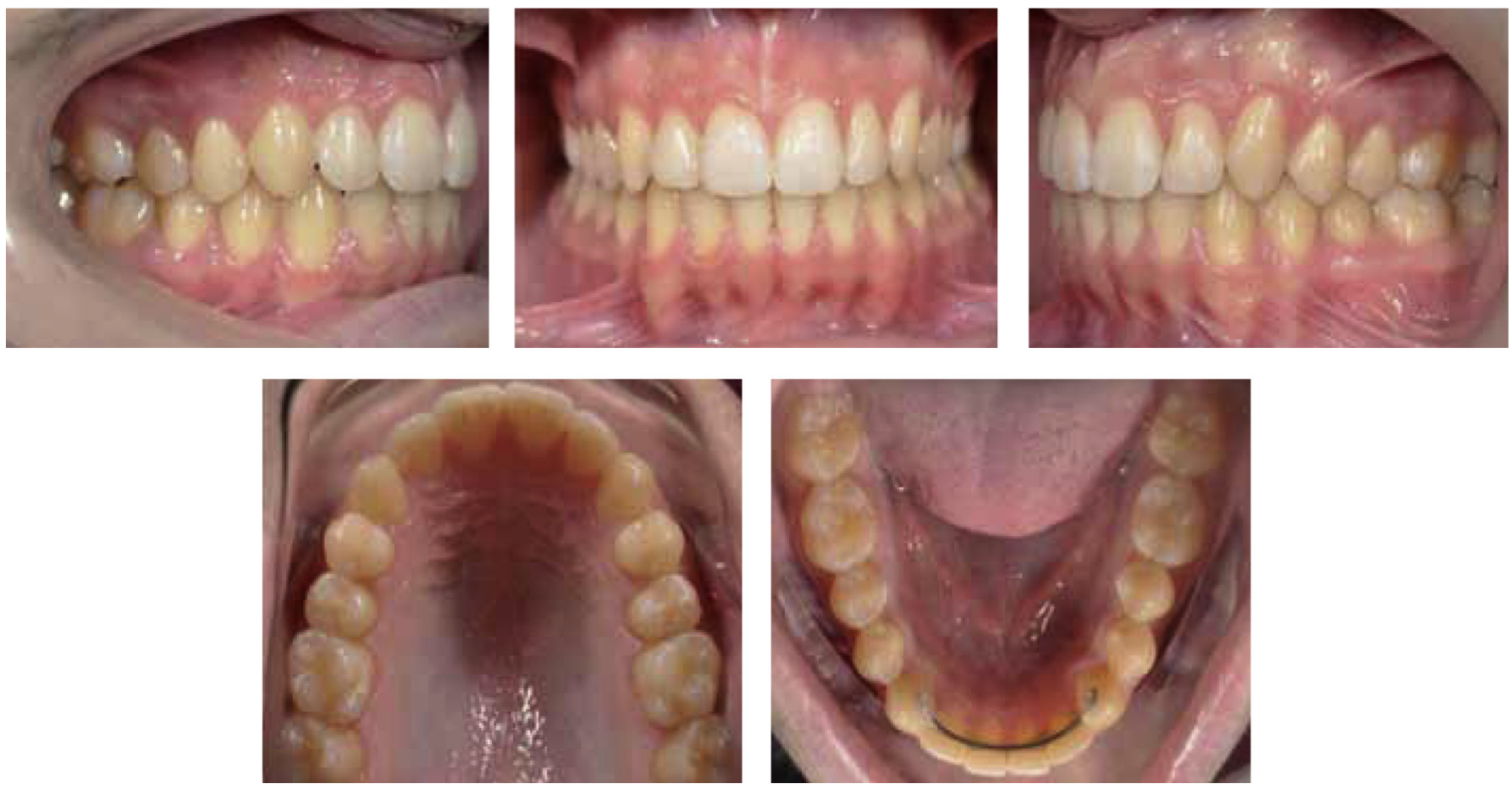

Figure 22

Normalization. Post-treatment intraoral views (+ 23 months). 

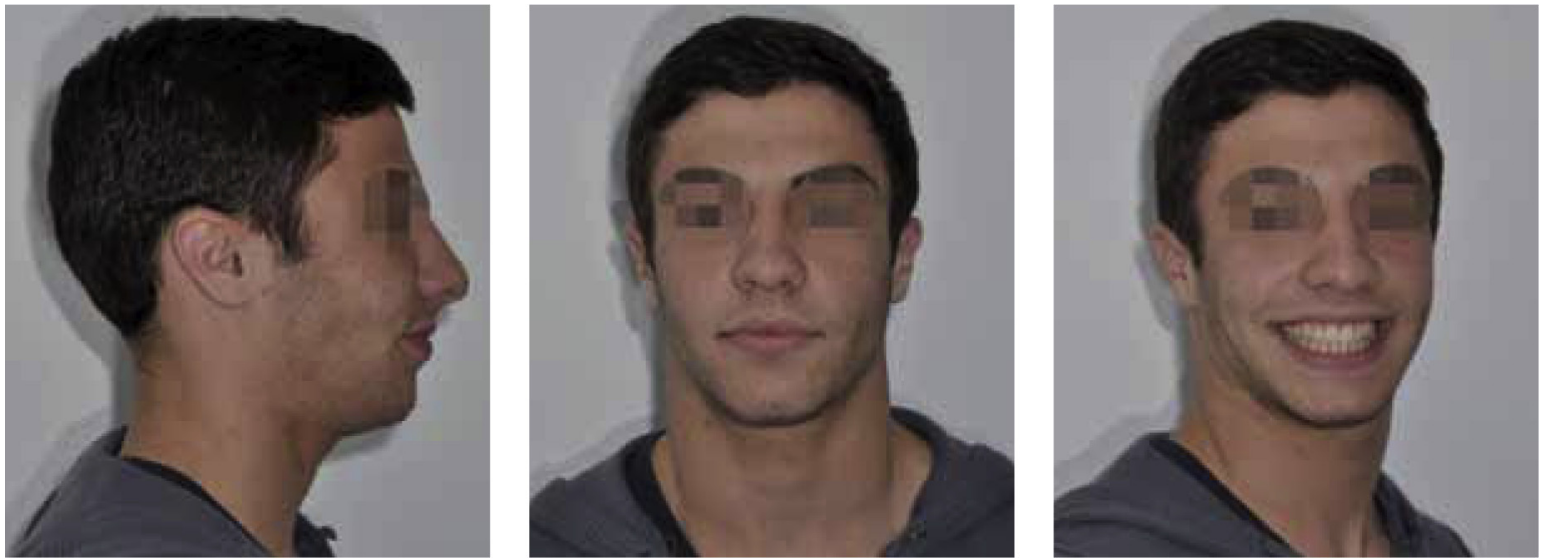

Figure 23

Post-treatment extraoral views.

pattern, D. Joris, 13 years old, presents with retruded mandible with a sagittal occlusal discrepancy of $7 \mathrm{~mm}$, anterior alveolar compensations and crowd-ing in both arches (Figs. 17 and 18). The $E$ space has been preserved to minimize the lack of space on the mandibular arch (Fig. 19). However, a 3 $\mathrm{mm}$ discrepancy persists at the beginning of treatment.

The treatment plan is established with the objectives of reducing the skeletal class II, normalizing the occlusion, uprighting the mandibular incisor. No extraoral or intraoral appliance is part of the treatment program, since the correction of the discrepancy will be managed by the specific mechanics with miniscrews. The miniscrews (1.2 mm diameter - $7 \mathrm{~mm}$ long) are inserted mesially into the maxillary molars (m6) and alternately use indirect and direct mechanics, with premolar by pass (Fig. 20). The post-therapeutic assessment was the following (Figs. 21 to 23):

- reduction of the class II: final ANB $=4.5^{\circ}$; initial $A N B=8^{\circ}$;
- uprighting of the incisor: final $\mathrm{FMIA}=60^{\circ}$; initial $\mathrm{FMIA}=55^{\circ}$;

- maintaining the vertical dimension: final FMA $=26^{\circ}$; initial FMA $=27^{\circ}$;

- length of treatment $=24$ months;

- wearing class || elastics $=0$;

- wearing extraoral force $=0$;

- wearing class III elastics $=2$ months;

- retention $=$ bonded retainer from 33 to 43.

\section{Case $n^{\circ} 3$}

Some cases of class III can also benefit from the advantages of this therapy that can be carried out in many possible combinations. We can insert the miniscrews on the inferior arch in a zone with or without teeth, for en masse or sectional retraction, with direct or indirect anchorage.

Laetitia is 13 years old and displays the morphological characteristics of a class III (Fig. 24). Facially, the deformation is moderate with, however, 

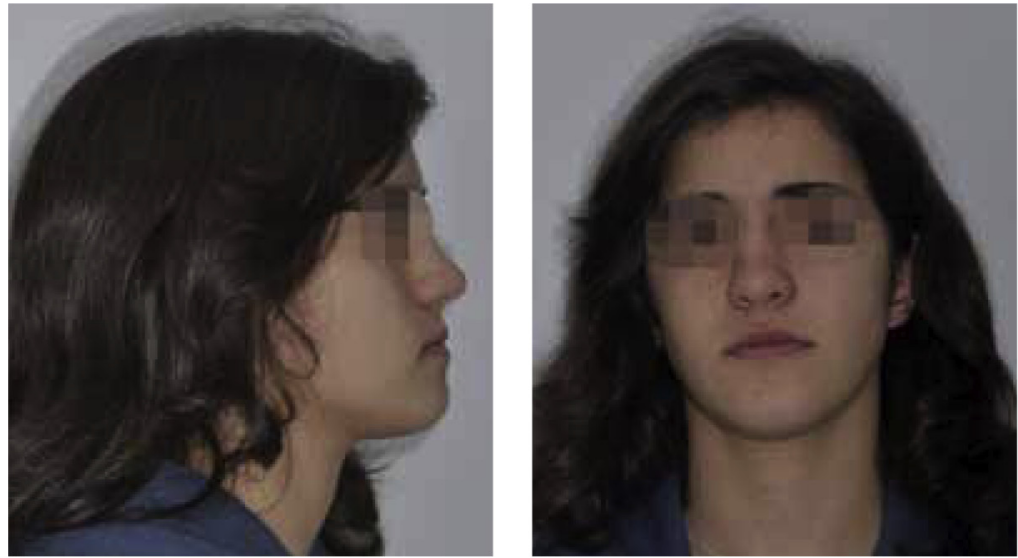

Figure 24

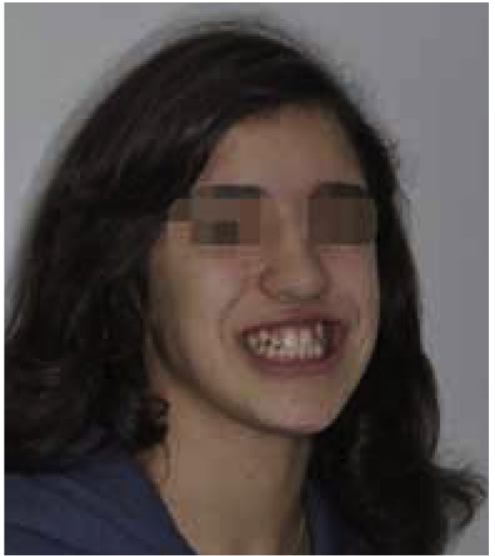

Extraoral views demonstrating a mild discrepancy between the jaws.
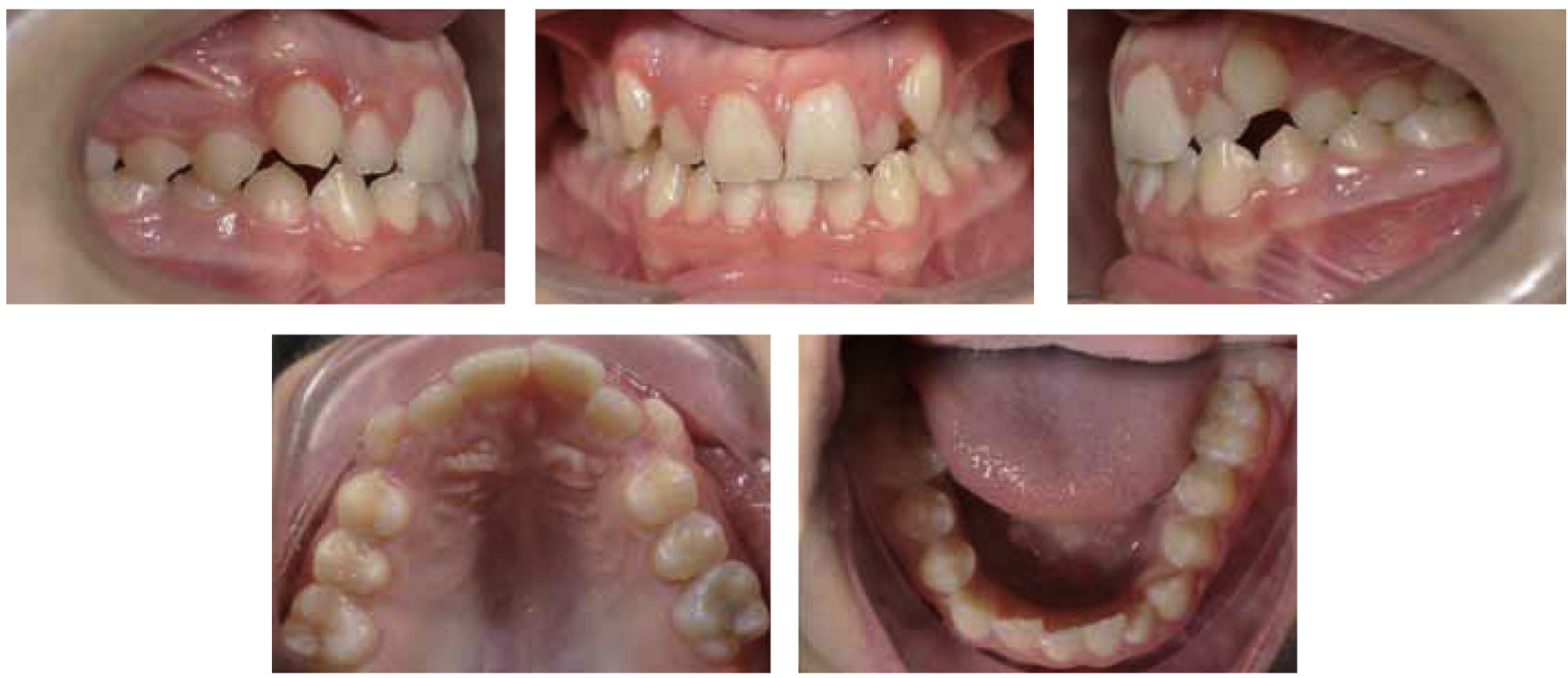

Figure 25

Intraoral views showing the anterior misalignment of 12 and 22, a slight left crossbite, a deviation of the midlines, a bilateral canine and molar class III and mandibular crowding of $5 \mathrm{~mm}$.

some growth to come; she has class III occlusal dental arch relationships, with no significant transverse problem and with crowding in both arches (Fig. 25). A lateral cephalometric xray shows a negative $A N B$ of $-4^{\circ}$, no vertical dysharmony and some slight alveolar compensations that are barely defined (Fig. 26). Without miniscrew anchorage, we can legitimately ask the question whether the four premolars should be extracted. Since the 


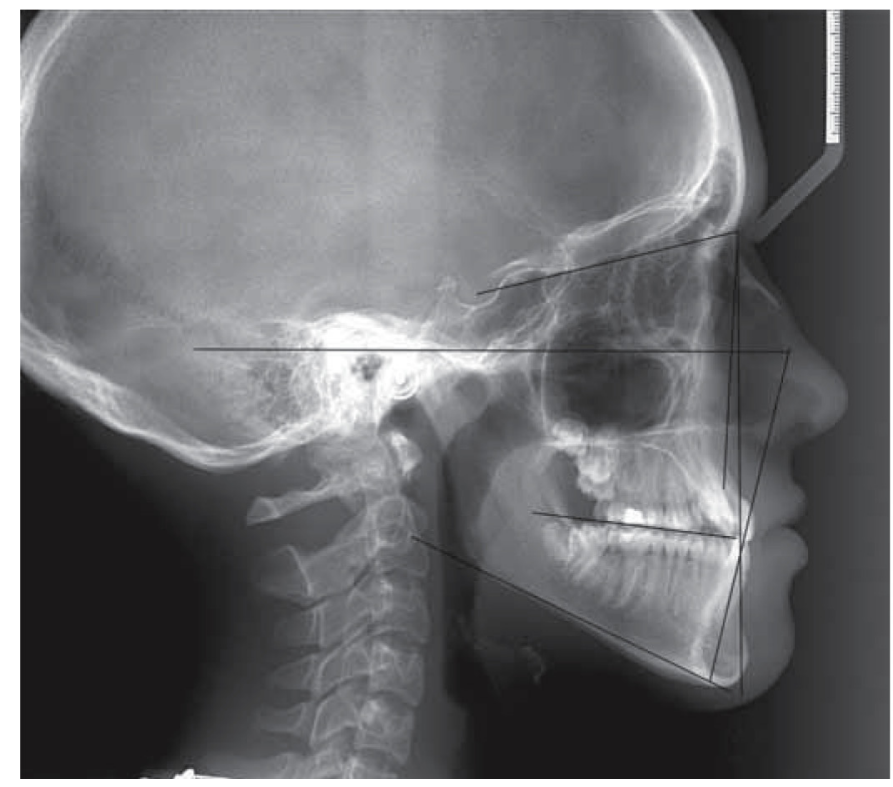

esthetic effects of the deformation are mild, a non-surgical treatment can reasonably be planned. In this case, the miniscrews will help provide the necessary anchorage to solve this problem without surgery, without extraction or any special patient cooperation.

A panoramic xray before treatment shows the presence of 3 wisdom teeth far enough impacted that should not interfere with the mandibular distalization. The space between the mandibular first and second molars is wide enough to become the most preferred insertion site for the miniscrews. The treatment plan is established as follows:

- levelling and aligning in the lower jaw, maxillary levelling/(1.5 diameter-7 $\mathrm{mm}$ long) mesially to 37 and 47 (mL7);

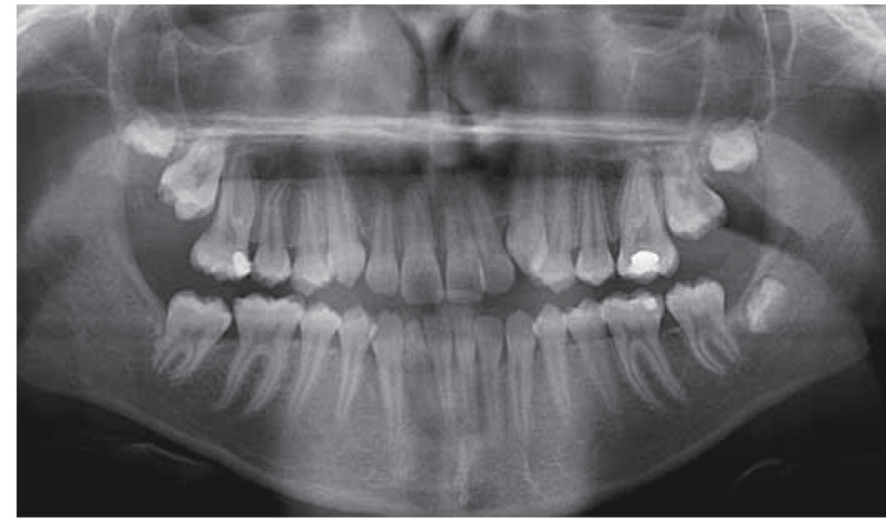

Figure 26

Xray before treatment that confirm the skeletal class II (ANB $=-4^{\circ}$, AoBo $\left.=-10 \mathrm{~mm}\right)$.

- correction of the molar and premolar relationships (Fig. 27);

- retraction of 33/43 with intramaxillary traction/incisor alignment;

- intercuspation.

The planned time frame is from 18 to 21 months.

The post therapeutic result is in line with our expectations. The objectives of creating normal occlusion, correcting the crowding without anterior displacement and not degrading facial relationships were all achieved with only one phase of therapy that was completed in 22 months (Figs. 29 and 30). The skeletal class III was improved, AoBo reduced from $-10 \mathrm{~mm}$ to $-3 \mathrm{~mm}$, the ANB going from $-4^{\circ}$ to $-2^{\circ}$ by reducing the SNB angle. The axial position of the mandibular incisors was unchanged $\left(\mathrm{FMIA}=76^{\circ}\right)($ Fig. 28). 

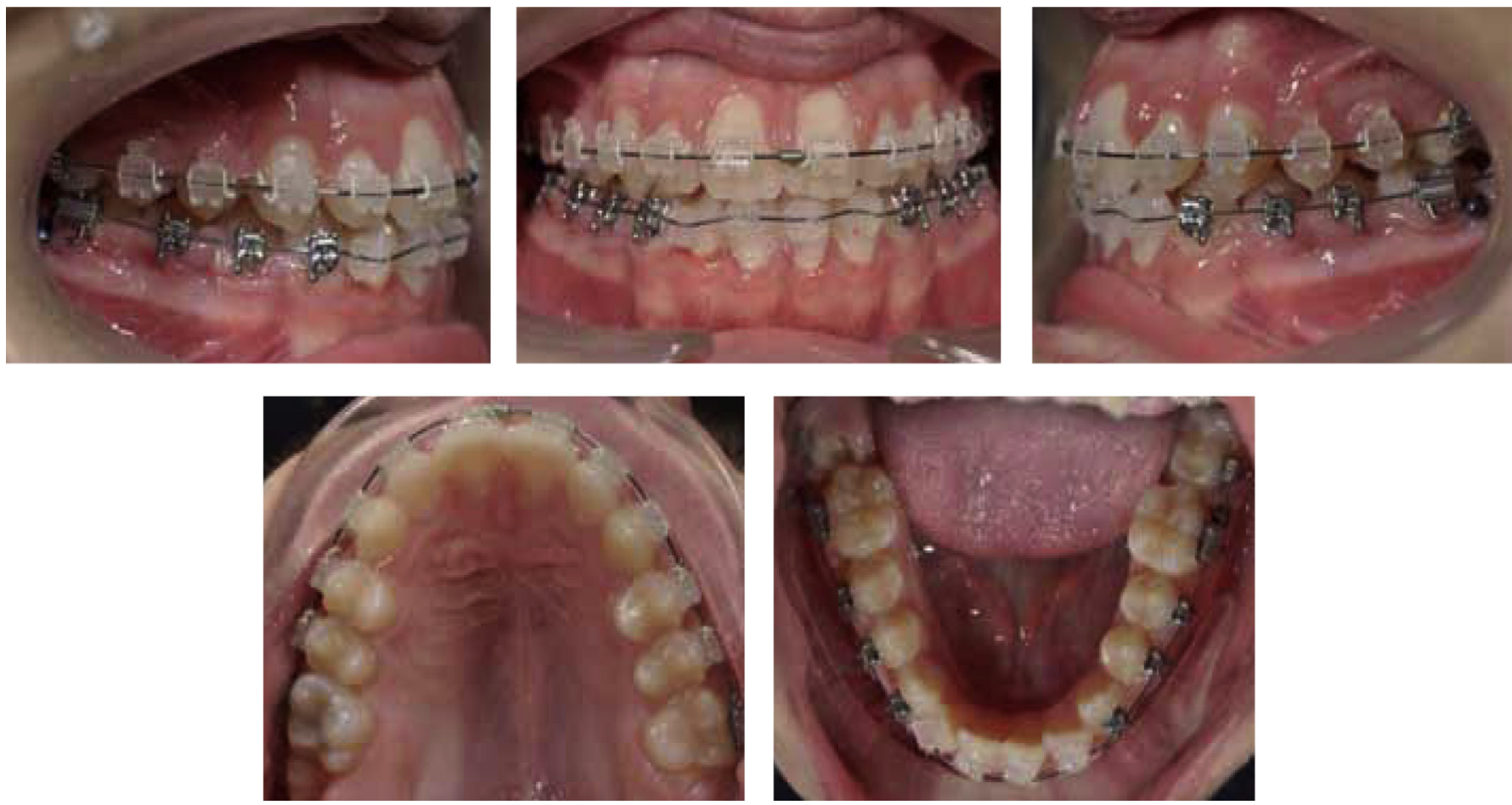

Figure 27

Phase of simultaneous leveling on the two arches under posterior-anterior traction with miniscrews in the $m L 7$ position.
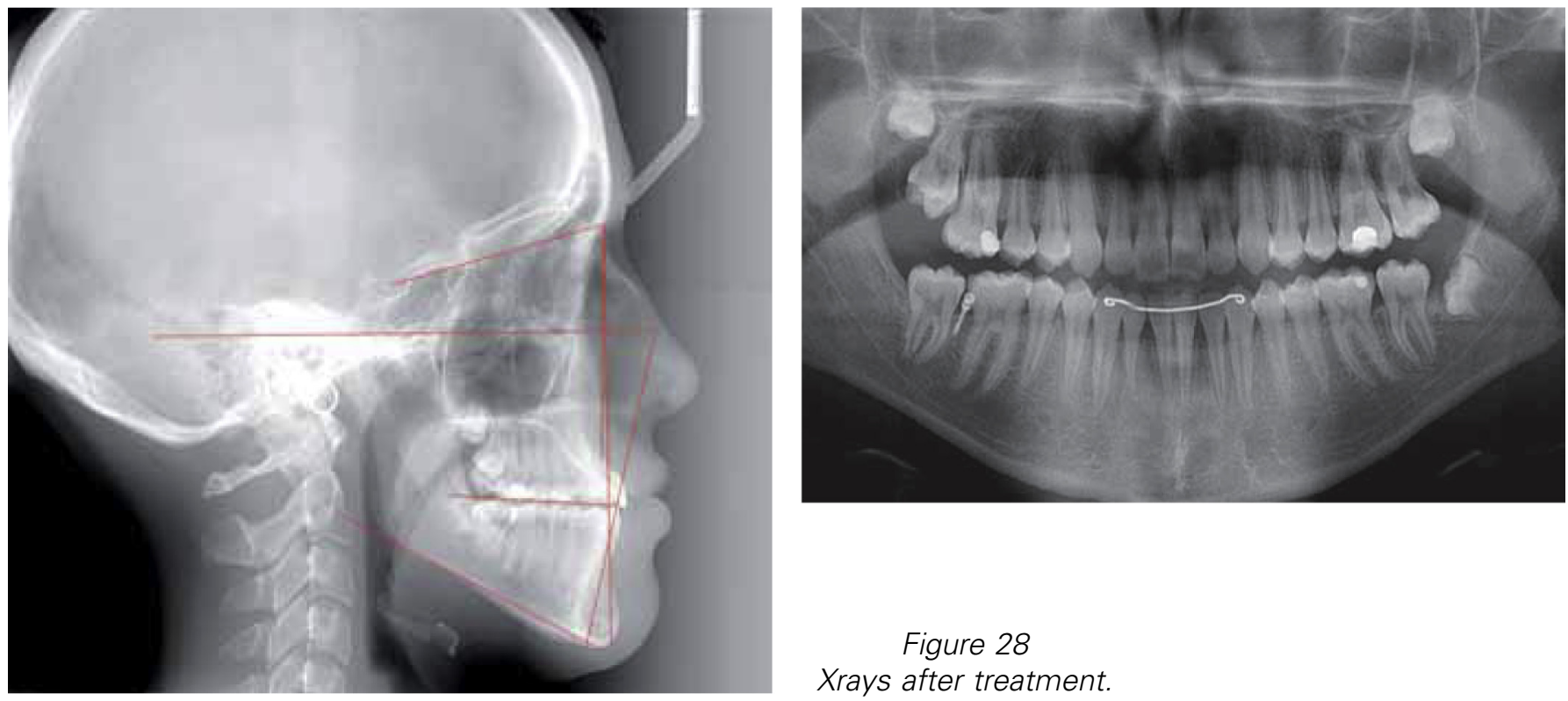

Figure 28

Xrays after treatment. 

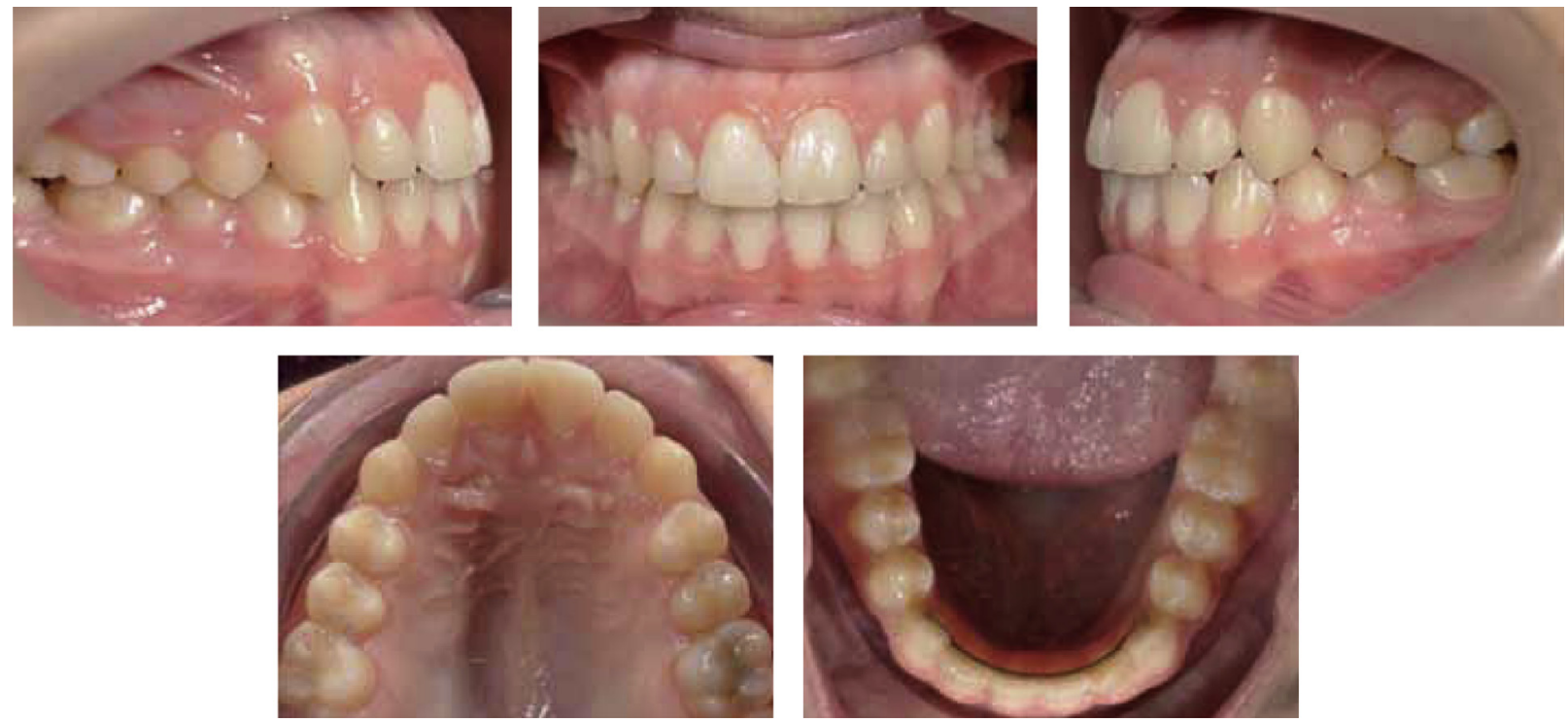

Figure 29

Post-treatment intraoral views with corrected arch relationships.
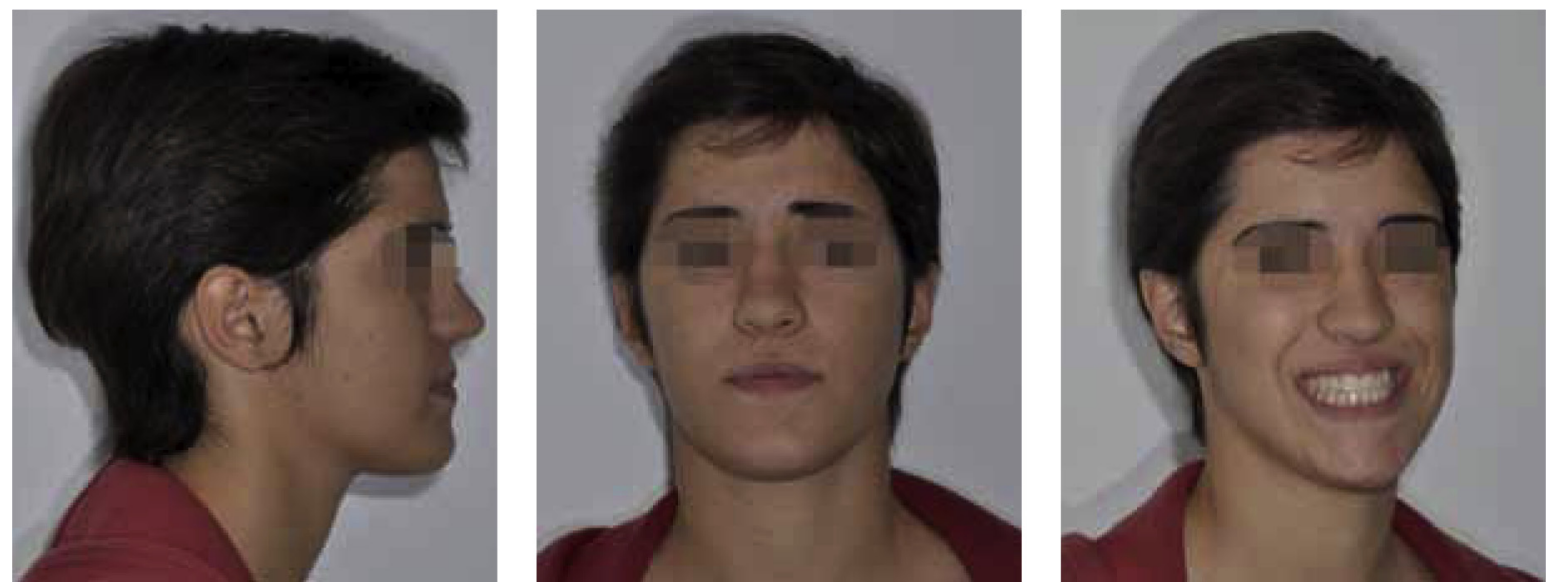

Figure 30

Post-treatment extraoral views.

\section{PERSPECTIVES}

Multibracket treatments with miniscrews are increasingly used on a daily basis by many clinicians. Our personal experience began in 2003 and for many years now we use them routinely in our practice and have a very clear protocol in place. Several studies that were testing our own therapeutic concepts, based on significant sampling of cases, 
obtained consistent results every time. So now, we would like to highlight some strong points:

- it is possible, using miniscrews in a well thought out manner and by respecting mechanical principles taking into account the principal existing factors, to achieve results that are completely reproducible from one patient to the next;

- it is possible to easily achieve increase of achorage in addition to the classically recognized conservation of anchorage. We observe an "absolute" resistance to the forces used on the one hand, and we can create available space in the arch on the other hand;

- undoubtedly the most important fact, that we also find reported by other authors ${ }^{63,74}$, is that now it

\section{CONCLUSION}

The few cases that we presented here provide a clinical translation of the many effects orthodontists can expect when they use miniscrews in orthodontic treatment. These cases show how the use of anchorage screws can positively impact the therapeutic outcome of treatment to correct dental and arch length discrepancies associated with Angle's Classes I, II and III. In addition to correcting the morphology, the length of treatment is shortened, the need for cooperation is reduced, the mechanics are controlled.

A new kind of orthodontics emerged from Asia ten years ago and its use is becoming more widespread every day. becomes possible to achieve retrusion and significant molar distalization especially on the upper arch; this opens up the field of indications and makes orthodontic treatment effective in a totally new way that takes it to the next level;

- the skeletal effects that we observed are extremely interesting and the first recorded data should be corroborated by randomized controlled trials with high external validity;

- miniscrews provide non-invasive anchorage that can be systematized for any type of patient (during growth, in the young adult or in the senior) and for any type of sagittal and transversal discrepancies.
The Newtonian duality of action-reaction is no longer relevant for mechanical orthodontics. Make room for Archimedes and his theory of levers and his screw. Now we can move teeth or groups of teeth with no secondary effects on the anchorage teeth. Moreover, we can achieve movements that have been impossible until now such as intrusion and molar ditalization. All of this offers new therapeutic perspectives and makes it possible for orthodontists to use miniscrews to develop a radically different and very effective approach to treatment when caring for children as well as adults.

Conflicts of interest: The author declares no conflict of interest. 


\section{BIBLIOGRAPHY}

1. Bae SM, Park HS, Kyung HM, Kwon OW, Sung JH. Clinical application of microimplant anchorage. J Clin Orthod 2002;36: 298-302.

2. Bae SM, Park HS, Kyung HM, Sung JH. Ultimate anchorage control. Tex Dent J 2002;119:580-591.

3. Baik UB, Chun YS, Jung MH, Sugawara J. Protraction of mandibular second and third molars into missing first molar spaces for a patient with an anterior open bite and anterior spacing. Am J Orthod Dentofacial Orthop 2012;141:783-95.

4. Baron P, Gualano C. Anchorage control performed with mini-screws and the Lingualjet Appliance. In: Echarri P, Takemoto K et al.: Nuevo Enfoque en Ortodoncia Lingual, Madrid: Ed. Ripano, 2010:15-26.

5. Baxmann M, McDonald F, Bourauel C, Jäger A. Expectations, acceptance, and preferences regarding microimplant treatment in orthodontic patients: A randomized controlled trial. Am J Orthod Dentofacial Orthop 2010;138(3):250.e1-250.e10.

6. Bellakehal A, Tewfik M. Étude par superpositions procustes des effets dentaires et squelettiques lors de la distalisation des premières molaires maxillaires sous mini-vis chez les patients en croissance. Mémoire Diplôme d'université d'orthodontie; université Toulouse III, 2012.

7. Benson PE, Tinsley D, O'Dwyer JJ. Midpalatal implants vs headgear for orthodontic anchorage - a randomized clinical trial: cephalometric results. Am J Orthod Dentofacial Orthop 2007;132:606-15.

8. Caravano A, Velo S, Leone P, Siciliani G. Clinical applications of the microscrew anchorage system. J Clin Orthod 2005;39:9-24.

9. Cheng SJ, Tseng IY, Lee JJ, Kok SH. A prospective study of the risk factors associated with failure of miniimplants used for orthodontic anchorage. Int J Oral Maxillofac Implants 2004;19:100-6.

10. Chiles D, Chilles JG. Un dispositif à ancrage squelettique pour la traction et la mise en place des canines incluses. Rev Orthop Dento-Fac 2009;43:67-88.

11. Cho NC, Park YC, JoYM, Lee KJ. Combined use of miniscrews and clear appliances for the treatment of bialveolar protrusion without conventional brackets. Am J Orthod Dentofacial Orthop 2009;135:671-81.

12. Choi BH, Zhu SJ, Kim YH. A clinical evaluation of titanium miniplates as anchors for orthodontic treatment. Am J Orthod Dentofacial Orthop 2005;128:382-4.

13. Cornelis MA, De Clerck HJ. Maxillary molar distalization with miniplates assessed on digital models: a prospective clinical trial. Am $J$ Orthod Dentofacial Orthop 2007;132:373-7.

14. Cornelis MA, Scheffler NR, De Clerck HJ, Tulloch JF, Behets CN. Systematic review of the experimental use of temporary skeletal anchorage devices in orthodontics. Am J Orthod Dentofacial Orthop 2007;131:S52-8

15. Costa A, Raffaini M, Melsen B. Miniscrews as orthodontic anchorage: a preliminary report. Int J Adult Orthod Orthognath Surg 1998;13:201-9.

16. Crismani AG, Bertl MH, Celar AG, Bantleon HP, Burstone CJ. Miniscrews in orthodontic treatment: review and analysis of published clinical trials. Am J Orthod Dentofacial Orthop 2010;137:108-13.

17. Darque F, Ellouze S. Biomécanique des mini-implants d'ancrage : illustrations cliniques. Intern Orthod 2007;5: 357-392.

18. Derton N, Derton R, Perini A. Forced eruption with miniscrews; inter-arch [corrected] method with vertical elastics versus intra-arch method using the Derton-Perini technique: two case reports. Intern Orthod 2011;9:179-95. 
19. Faure J, Oueis A. Mini-vis : protocole et mécanique dans les dysmorphies de classe II. Rev Orthop Dento Fac 2011;45:57-74.

20. Feldman L, Bondemark L. Orthodontic anchorage: a systematic review. Angle Orthod 2006;76:493-501.

21. Feldmann I, Bondemark L. Anchorage capacity of osseointegrated and conventional anchorage systems: a randomized controlled trial. Am J Orthod Dentofacial Orthop 2008;133:339.e19-339.e28.

22. Feng X, Li J, Li Y, Zhao Z, Zhao S, Wang J. Effectiveness of TAD-anchored maxillary protraction in late mixed dentition. A systematic review. Angle Orthod 2012; $82: 1107-14$

23. Frendenthaler JW, Haas R, Bantleon HP. Bicortical titanium screws for critical orthodontic anchorage in the mandible: a preliminary report on clinical applications. Clin Oral Implants Res 2001;12:358-63.

24. Garfinkle JS, Cunningham LL Jr, Beeman CS. Evaluation of orthodontic mini-implant anchorage in premolar extraction therapy in adolescents. Am J Orthod Dentofacial Orthop 2008;133:642-53.

25. Gelgör IE, Büyükyilmaz T, Karaman Al, Dolanmaz D, Kalayci A. Intraosseous screwsupported upper molar distalization. Angle Orthod 2004;74:838-50.

26. Gritsch $\mathrm{K}$, et al. A systematic review of methods for tissue analysis in animal studies on orthodontic miniimplants. Orthod Craniofac Res 2012;15:135-47.

27. Gunduz E, Schneider-Del Savio TT, Kucher G, Schneider B, Bantleon HP. Acceptance rate of palatal implants: a questionnaire study. Am J Orthod Dentofacial Orthop 2004;126:623-6.

28. Herman R, Frans-Currier G, Miyake A. Mini-implant anchorage for maxillary canine retraction: A pilot study. Am J Orthod Dentofacial Orthop 2006;130:228-35.

29. Hong RK, Heo JM, Ha YK. Lever-arm and mini-implant system for anterior torque control during retraction in lingual orthodontic treatment. Angle Orthod 2005; 75:129-41.

30. Huang $X$, Han P. Comparison of clinical effects between screw-implant and extraforce as anchorage. Beijing J Stomatol 2007;15:213-5.

31. Kinzinger G, Fuhrmann R, Gross U, Diedrich P. Modified pendulum appliance including distal screw and uprighting activation for non-compliance therapy of Class II malocclusion in children and adolescents. J Orofac Orthop 2000;61:175-90.

32. Kuroda S, Katayama A, Takano-Yamamoto T. Severe anterior open-bite case treated using titanium screw anchorage. Angle Orthod 2004;74:558-67.

33. Kuroda S, Sugawara Y, Deguchi T, Kyung HM, Takano-Yamamoto T. Clinical use of miniscrewimplants as orthodontic anchorage: success rates and postoperative discomfort. Am J Orthod Dentofacial Orthop 2007;131:9-15.

34. Kuroda S, Sugawara Y, Tamamura N, Takano-Yamamoto T. Anterior open bite with temporomandibular disorder treated with titanium screw anchorage: evaluation of morphological and functional improvement. Am $\mathrm{J}$ Orthod Dentofacial Orthop 2007; 131:550-60.

35. Kuroda S, Yamada K, Deguchi T, Kyung HM, Takano-Yamamoto T. Class II malocclusion treated with miniscrew anchorage: Comparison with traditional orthodontic mechanics outcomes. Am J Orthod Dentofacial Orthop 2009;135:302-9.

36. Kyung HM, Park HS, Bae SM, Sung JH. Development of orthodontic micro-implants for intraoral anchorage. J Clin Orthod 2003;37:321-8.

37. Kyung HM, Park HS, Bae SM, Sung JH, Kim IB. The lingual plain-wire system with micro-implant anchorage. J Clin Orthod 2004;38:388-95.

38. Lagravère MO, Carey J, Heo G, Toogood RW, Major PW. Transverse, vertical, and anteroposterior changes from bone-anchored maxillary expansion vs traditional rapid maxillary expansion: A randomized clinical trial. Am J Orthod Dentofacial Orthop 2010;137:304. e1-304.e12. 
39. Lai EH, Yao CC, Chang JZ, Chen I, Chen YJ. Threedimensional dental model analysis of treatment outcomes for protrusive maxillary dentition: comparison of headgear, miniscrew, and miniplate skeletal anchorage. Am J Orthod Dentofacial Orthop 2008;134:636-45.

40. Lakhassassi W. Étude par superpositions procustes des déplacements dentaires et squelettiques lors des traitements multibagues par mini-vis. Mémoire Diplôme d'université d'orthodontie ; université Toulouse III, 2009.

41. Lee JS, Park HS, Kyung HM. Micro-implant anchorage for lingual treatment of a skeletal Class II malocclusion. J Clin Orthod 2001;35:643-7.

42. Lee W, Wong RW, Ikegami T, Hägg U. Maxillary second molar extractions in orthodontic treatment. World J Orthod 2008;9:52-61.

43. Li F, et al. Comparison of anchorage capacity between implant and headgear during anterior segment retraction. Angle Orthod 2011;81:915-22.

44. Ma J, Wang L, Zhang W, Chen W, Zhao C, Smales RJ. Comparative evaluation of micro-implant and headgear anchorage used with a pre-adjusted appliance system. Eur J Orthod 2008;30:283-7.

45. Majzoub Z, Finotti M, Miotti F. Bone response to orthodontic loading of endosseous implants in the rabbit calvaria. Eur J Orthod 1999;33:373-81.

46. Melsen B. Indications d'ancrage squelettique en orthodontie. Rev Orthop Dento Fac 2006;40:41-61.

47. Miyawaki S, Koyama I, Inoue M, Mishima K, Sugahara T, Takano-Yamamoto T. Factors associated with the stability of titanium screws placed in the posterior region for orthodontic anchorage. Am J Orthod Dentofacial Orthop 2003;124:373-8.

48. Nabbout F, Faure J, Baron P, Braga J, Treil J. Tooth anchorage in orthodontics: scanner-generated data. Intern Orthod 2004;2:241-56.

49. Nabbout F, Faure J, Baron P, Braga J, Treil J. Centers of resistance of tooth segments and orthodontic mechanics. Intern Orthod 2007;5:437-46.

50. Oh YE, Park HS, Kwon TG. Treatment effects of microimplant-aided sliding mechanics on distal retraction of posterior teeth. Am J Orthod Dentofacial Orthop 2011;139:470-81.

51. Oz AA, Arici N, Arici S. The clinical and laboratory effects of bracket type during canine distalization with sliding mechanics. Angle Orthod 2012;82:326-32.

52. Papadopoulos MA. Orthodontic treatment of Class II malocclusion with miniscrew implants. Am J Orthod Dentofacial Orthop 2008;134:604.e1-604.e16.

53. Papadopoulos MA, Melkos AB, Athanasiou AE. Noncompliance maxillary molar distalization with the first class appliance: a randomized controlled trial. Am J Orthod Dentofacial Orthop 2010;137:586.e1-586.e13.

54. Paradis L. Étude des déplacements dentaires et squelettiques lors des traitements multibagues utilisant des mini-vis en position latéro-maxillaire. Mémoire Certificat d'études cliniques spéciales mention orthodontie; université Toulouse III, 2008.

55. Park HS. The skeletal cortical anchorage using titanium microscrew implants. Korean J Orthod 1999;29:699-706.

56. Park HS, Bae SM, Kyung HM, Sung JH. Micro-implant anchorage for treatment of skeletal Class I bialveolar protrusion. J Clin Orthod 2001;35:417-22.

57. Park HS, Bae SM, Kyung HM, Sung JH. Simultaneous incisor retraction and distal molar movement with microimplant anchorage. World J Orthod 2004;5:164-71.

58. Park HS, Kwon TG, Sung JH. Non extraction treatment with microscrew implants. Angle Orthod 2004;74:539-49.

59. Park HS, Jeong SH, Kwon OW. Factors affecting the clinical success of screw implants used as orthodontic anchorage. Am J Orthod Dentofacial Orthop 2006;130:18-25.

60. Park HS, Kwon TG. Sliding mechanics with microscrew implant anchorage. Angle Orthod 2004;74:703-10. 
61. Park HS, Lee SK, Kwon OW. Group distal movement of teeth using micros crew implant anchorage. Angle Orthod. 2005;75:602-609.

62. Park YC, Choi YJ, Lee JS, Hwang HS. Déplacement distal des molaires supérieures à I'aide d'implants mini-vis. Rev Orthop Dento Fac. 2006;40:93-110.

63. Park YC, Lee SY, Kim DH, Jee SH. Intrusion of posterior teeth using mini screw implants. Am J Orthod Dentofacial Orthop 2003;123:690-694.

64. Razavi MR. Molar intrusion using miniscrew palatal anchorage. J Clin Orthod 2012;46(8):493-8.

65. Senısık NE, Türkkahraman H. Treatment effects of intrusion arches and mini-implant systems in deepbite patients. Am J Orthod Dentofacial Orthop 2012;141(6):723-33.

66. Sugawara J, et al. Treatment and posttreatment dentoalveolar changes following intrusion of mandibular molars with application of a skeletal anchorage system (SAS) for open bite correction. Int J Adult Orthod Orthognath Surg 2002;17:243-53.

67. Sugawara J, Daimaruya T, Umemori M. Distal movement of mandibular molars in adult patients with the skeletal anchorage system. Am J Orthod Dentofacial Orthop 2004;125:130-8.

68. Sung JH, Park HS, Kyung HM, Kwon OW, Kim IB. L'ancrage des micro-implants dans le système des forces directionnelles. International Orthodontics 2004;2:137-61.

69. Tai K, Park JH, Tanino M, Ikeda K. Bimaxillary dentoalveolar protrusion treated with lingual appliances and temporary anchorage devices. J Clin Orthod. 2012;46:739-46.

70. Umemori M, Sugawara J, Mitani H, Nagasaka H, Kawamura H. Skeletal anchorage system for openbite correction. Am J Orthod Dentofacial Orthop 1999;115:166-74.

71. Upadhyay M, Yadav S, Nagaraj K, Patil S. Treatment effects of mini-implants for enmasse retraction of anterior teeth in bialveolar dental protrusion patients: A randomized controlled trial. Am J Orthod Dentofacial Orthop 2008;134:18-29.

72. Wiechmann D, Meyer U, Bûchter A. Success rate of mini- and micro-implants used for orthodontic anchorage: a prospective clinical study. Clin Oral Implants Res 2007; 18:263-7.

73. Wilmes B, Nienkemper M, Ludwig B, Kau CH, Pauls A, Drescher D. Esthetic Class II treatment with the Beneslider and aligners. J Clin Orthod 2012;46:390-8.

74. Yamada K, Kuroda S, Deguchi T, Takano-Yamamoto T, Yamashiro T. Distal movement of maxillary molars using miniscrew anchorage in the buccal interradicular region. Angle Orthod 2009;79:78-84. 